\title{
Sorption modelling by Gibbs energy minimisation: Towards a uniform thermodynamic database for surface complexes of radionuclides
}

\author{
By Dmitrii A. Kulik* \\ Waste Management Laboratory, Paul Scherrer Institute, CH-5232 Villigen PSI, Switzerland
}

(Received August 20, 2001; accepted April 11, 2002)

\author{
Radionuclide retention / Surface complexation modelling / \\ Standard thermodynamic properties / \\ Gibbs energy minimisation / Uranium(VI) / \\ Performance assessment
}

\begin{abstract}
Summary. Radionuclide sorption on mineral-water interfaces can be thermodynamically modelled, similar to solid-solution aqueous-solution systems (only in chemical elemental stoichiometry), if definitions of the standard and reference states, surface activity terms (SAT), and elemental stoichiometries of surface-bound species are unequivocally established. A pre-requisite is that a unique common value of the reference (site) density $\left(\Gamma_{\mathrm{o}}\right)$ must be part of the definitions of standard and reference states, while the sample- and surfacespecific maximum density parameters $\left(\Gamma_{\max }\right)$ be included into the SAT corrections to reproduce saturation of physically available adsorption sites instead of introducing the additional mass balance constraints. Subsequently, the standard partial molal properties of surface complexes at multiple surface types on different sorbents can be found, comparable with the standard molar properties of solids, gases and aqueous species. Using surface complexation models (SCM) of U(VI) adsorption on quartz and amorphous silica $\left(\mathrm{SiO}_{2}\right)$ phases in GEM (Gibbs energy minimization) implementation, a feasible way is shown how to construct a uniform, internally consistent thermodynamic dataset for surface species of radionuclides; to use standard partial molal Gibbs energies $G_{298}^{\text {o }}$ of surface species in sorption modelling; how to convert $G_{298}^{\text {o }}$ values from/to $\log K$ or intrinsic adsorption constants $\log K^{\text {int }}$ to use in the law-of-mass action (LMA) speciation codes, and finally, into "smart $K_{\mathrm{d}}$ " values for the applications related to waste repository performance assessment.
\end{abstract}

\section{Introduction}

Distribution coefficients $\left(K_{\mathrm{d}}\right)$ are traditionally used in nuclear waste disposal performance assessment (PA) to describe sorption of radionuclides $[1,2]$. If an internally consistent thermodynamic database (TDB) for surface complexes would exist then PA studies could benefit from the modelling of adsorption equilibria to generate "smart" $K_{\mathrm{d}}$ values for the "sorption-controlled" elements, varying in re-

\footnotetext{
*E-mail: dmitrii.kulik@psi.ch
}

sponse to the changing physicochemical conditions in the repository.

At present, most of the aqueous/surface speciation models are based on the "quantitative treatment of adsorption reactions that stems from considering aqueous surface speciation at the solid-water interface, and applying mass balances and thermodynamic mass action laws that are analogous to those used for modelling speciation in solution" [1]. However, the related intrinsic adsorption constants $K^{\text {int }}$, used in Law-of-Mass Action (LMA) algorithms (e.g. $[3,4])$, may not be directly compared between different surfaces of different solid sorbents because the $K^{\text {int }}$ values appear to depend on the total site density $\Gamma_{\mathrm{T}}$ (related to surface) and/or maximum $\Gamma_{\max }$ density (related to surface species) $[5,6]$. These two densities are typically mixed into one generic "site density parameter" in LMA surface complexation models (SCM) $[1,7,8]$, even though $\Gamma_{\max }$ must not necessarily coincide with $\Gamma_{\mathrm{T}}$. The values of $K^{\text {int }}$ may also depend on the choice of electrostatic model of the solid-water interface.

It has long been recognised that fitting at the same value of $\Gamma_{\mathrm{T}}$ for the same (e.g. Generalised Double Layer) model is essential for obtaining a consistent set of $K^{\text {int }}$ for different metals even on one oxide sorbent $[7,9]$. Nevertheless, it remains unclear how the $K^{\text {int }}$ values fitted at different $\Gamma_{\mathrm{T}}$ parameters can be consistently compared between different surfaces of a mineral particle and even between different minerals, as it has been attempted recently [10] for the triple layer model (TLM). The LMA SCMs require the separate mass-balance constrains of the form $N_{t, s}=A_{\mathrm{T}} \Gamma_{\mathrm{T}}$, (where $A_{\mathrm{T}}$ is the total surface area in $\mathrm{m}^{2}$, and $\Gamma_{\mathrm{T}}$ is density in $\mathrm{mol} \mathrm{m}^{-2}$ ) to be set for each surface/site type. This may overcomplicate a multi-site-surface LMA SCM, and also may obscure the role of stability of the mineral sorbent in the multi-phase sorption equilibria.

Uptake of radionuclides may also take place in solidsolution aqueous-solution (SSAS) systems, such as carbonates or cement phases, for which application of the LMA models becomes cumbersome. However, even the highorder multiphase non-ideal SSAS equilibria are easy to solve using the GEM algorithms [11-13], if the standard molar properties of the solid-solution end-members (+ optionally, excess mixing parameters) are known or can be retrieved Brought to you by | Lib4RI Eawag-Empa 
from the experimental or natural solubility data. Hence, addition of surface complexation to the SSAS models (already run with GEM algorithms) is desirable and seems to be possible, although this requires knowledge of the standard molar properties of surface complexes. Can stability of surface species be considered alike that of the solid solution, aqueous, and gaseous species, and the surface sorption on mineral sorbents treated similar to the mixing in the (non-ideal) solid-solution phases? Positive answers would allow the "sorption continuum" to be modelled only in chemical elemental stoichiometry, without additional balance constraints for surface sites, and with several multi-site-surface sorption phases included into the aquatic system together with gas phase, solid solutions, and fixed-composition minerals.

Recent studies $[14,15]$ show that such thermodynamic sorption modelling is indeed possible (even at hydrothermal conditions), if unequivocal definitions of the standard and reference states for surface species, surface activity terms (SAT), and chemical elemental stoichiometry of surface functional groups and complexes can be provided. Then, the standard partial molal properties of surface species can be determined, comparable between all (hydr)oxide mineral surfaces and consistent to the standard properties of solids, gases and aqueous species; collected into a uniform thermodynamic database; and, if necessary, converted into thermodynamic equilibrium constants $K$ and intrinsic adsorption constants $K^{\text {int }}$ for any site density parameter $\Gamma_{\mathrm{T}} \neq \Gamma_{\mathrm{o}}$ for usage in the LMA speciation codes. It may even be possible to modify the LMA code by introducing calculation of the SAT together with the aqueous activity coefficients, and in this way circumvent introduction of the additional $N_{t, s}$ mass balance constraints. The GEM approach to calculate equilibria with surface complexation is preferred in this contribution because of a capability to calculate multi-site-surface sorpion generally in the same way and together with the solid solutions and gases in the chemical elemental stoichiometry, directly using the standard thermochemical data. This approach is implemented in a GEM-Selektor computer code (http://les.web.psi.ch/Software/GEMS-PSI).

Thus, the main objective of the present contribution was to show (illustrated with examples of $\mathrm{U}(\mathrm{VI})$ adsorption on quartz and amorphous silica phases) a feasible way towards a uniform, internally consistent set of standard partial molal Gibbs energies $G_{298}^{o}$ of the actinide surface species, and to its usage (with that of aqueous species, gases and minerals) in GEM sorption modeling, as well as in conversions to/from $\log K$ for the LMA codes and into the "smart $K_{\mathrm{d}}$ " values for the applications related to (nuclear) waste disposal.

\section{Standard and reference states of surface species}

The standard state definition must describe a unique (equilibrium) state of the system to which all other states of interest are compared [16]. In SCMs, the surface species are usually treated similar to aqueous complexes, i.e. the standard state is assumed to be 1 mole of the species per $1 \mathrm{~kg}$ of $\mathrm{H}_{2} \mathrm{O}$-solvent (or per $1 \mathrm{~L}$ of solution) at zero charge and potential $\Psi=0[1,7]$. A problem hidden there is that infinitely many systems can contain $1 \mathrm{M}$ of a surface species at $\Psi=0$, but at different mole quantity $X_{\mathrm{a}, \mathrm{v}}$ and specific surface area $A_{\mathrm{a}, \mathrm{v}}$ of the $\alpha$-th sorbent. Conversely, the balance constraints like total moles of surface sites $N_{t, s}=A_{\mathrm{T}} \Gamma_{\mathrm{T}}$ contain the same ambiguity (many products of total surface $A_{\mathrm{T}}$ by site density $\Gamma_{\mathrm{T}}$ may result in the same value of $N_{t, s}$ ) and thus obscure the relations between the surface density $(\Gamma)$ and the activity $(a)$ of a particular surface species and quantity and specific surface area of the sorbent. This does not let us to define strictly such quantities as surface concentration, activity and activity coefficients. Hence, more parameters must be fixed at the standard state for the surface species than for the aqueous solutes.

Therefore, we put forward a concept of "sorption phase" that combines a mineral sorbent (1) with a prescribed specific surface area $A_{\mathrm{a}, \mathrm{v}}\left(\mathrm{m}^{2} \mathrm{~g}^{-1}\right)(2)$, covered with a monolayer of primary neutral amphoteric surface functional groups ("surface solvent") (3), part of which on different surface types (4) can react with the aqueous sorbates forming surface complexes (5). The standard state of surface species must define a unique combination of quantities (1) to (5), also compatible with the standard states chosen for minerals, water and aqueous species. This is possible only if a unique value of the reference density $\Gamma_{\mathrm{o}}$ is fixed for all mineral-water surfaces, as in a definition: The standard state of a surface species is when 1 mole of it occupies all sites of reference total density $\Gamma_{\mathrm{o}}$ on all the surface of 1 mole of the sorbent suspended in $1 \mathrm{~kg}$ of water-solvent at $P_{\mathrm{o}}=1 \mathrm{bar}$ and defined $T$, in absence of external fields and at zero surface potential $\Psi=0[14,15,17]$.

Conventional value $\Gamma_{\mathrm{o}}=2 \times 10^{-5} \mathrm{~mol} \mathrm{~m}^{-2} \approx 12.05 \mathrm{~nm}^{-2}$ is proposed because it roughly corresponds to the density of $\mathrm{H}_{2} \mathrm{O}$ molecules in a surface monolayer. Close values have been measured on rutile and other simple oxide surfaces e.g. using the tritium exchange technique [7]; recently, the total surface hydroxyl densities of 10 to $30 \mu \mathrm{mol} \mathrm{m}^{-2}$ (average $23.7 \mu \mathrm{mol} \mathrm{m}^{-2}$ ) were measured on a number of oxides using the Grignard method [18]. To a good extent, the value $\Gamma_{\mathrm{o}}=20 \mu \mathrm{mol} \mathrm{m}{ }^{-2}$ represents a realistic maximal density of monodentate surface complexes and can be used also as a default maximum site density parameter, if no independent information is available. In fact, any other, smaller or greater value of $\Gamma_{\mathrm{o}}$ could have been chosen; the only requirement is that it is fixed the same for all mineral-water interfaces. This choice is practical and is equivalent to the choice of $1 \mathrm{~kg}(55.5087 \mathrm{~mol})$ of $\mathrm{H}_{2} \mathrm{O}$ solvent in the standard state of aqueous species.

The reference state of a surface species has also been assumed to be similar to that of an aqueous species, e.g. unimolal at a hypothetical infinite dilution and at $\Psi=0$ [7]. At infinite dilution of all dissolved species, concentration of $\mathrm{H}_{2} \mathrm{O}$-solvent approaches another reference state of the activity equal to unity mole fraction (i.e. pure substance). In the classic $2 \mathrm{p} K$ SCMs [7-9, 19,20], the clean mineral (oxide) surface in presence of water is thought to be initially covered by the neutral surface functional groups $\equiv \mathrm{OH}^{\mathrm{o}}$, which to some extent can be (de)protonated or consumed to form surface complexes with aqueous sorbates ${ }^{l}$.

\footnotetext{
${ }^{1}$ Alternative, $1 \mathrm{p} K$ SCMs without accounting for the $\equiv \mathrm{OH}^{\circ}$ groups are also developed, but consideration of them is beyond the scope of this contribution.
} 
Logically, the hypothetical reference state of the $\equiv \mathrm{OH}^{\circ}$ group (a "surface solvent") should occur when all such groups are free (non-reacted) and occupy the sorbent surface in a monolayer of reference density $\Gamma_{\mathrm{o}}, e . g .1 \mathrm{~mol}$ of $\equiv \mathrm{OH}^{\circ}$ groups on a sorbent with reference total surface area $A_{\mathrm{o}}=1 / \Gamma_{\mathrm{o}}=5 \times 10^{5} \mathrm{~m}^{2} \mathrm{~mol}^{-1}$ per $1 \mathrm{~kg}$ of $\mathrm{H}_{2} \mathrm{O}$. The reference state of a surface complex (reacted $\equiv \mathrm{OH}^{\circ}$ functional group) then occurs at a hypothetical unimolal concentration and infinitely low surface density $[14,15]$. These two reference states are reciprocal to the same extent as the states used for the water-solvent and solutes in the aqueous electrolyte phase, respectively. Upon infinite dilution of aqueous sorbates, all the reference states for surface and aqueous species are correctly approached. The definitions of standard and reference states used in this contribution are conceptually related to the amphoteric (hydr)oxide surfaces. However, a reasonable choice of elemental stoichiometry of the "surface solvent", without including part of the sorbent stoichiometry (see below), will make the present thermodynamic treatment applicable to other, non-oxide or nonamphoteric surfaces (i.e. carbonates, sulfides, permanentcharge siloxane planes of clay particles or micas), as long as the surface complexation is thought to occur within a monolayer of the surface-coordinated water molecules.

The above definitions make description of activities and (electro)chemical potentials of the surface-bound species possible at any state of interest of a multi-site-surface sorption phase. It can be shown [15] that concentration of a surface species expressed as a surface density (mole) fraction $\Gamma_{j} / \Gamma_{\mathrm{o}}$ is invariant to the mole quantity $X_{\alpha, v}$ and specific surface area $A_{\alpha, v}$ of the sorbent. Using the $\Gamma_{j} / \Gamma_{\mathrm{o}}$ concentration, activity of $j$-th monodentate surface species (at $\Psi=0$ ) can be expressed as:

$$
a_{j}=\frac{\Gamma_{j}}{\Gamma_{\mathrm{o}}} \Xi_{j}=\frac{A_{\alpha, \mathrm{v}}^{\mathrm{o}} x_{j}}{\phi_{\alpha, \mathrm{t}} A_{\alpha, \mathrm{v}} X_{\alpha, \mathrm{v}}} \Xi_{j},
$$

where the "v" subscript denotes a "volume" part of the $\alpha$-th sorption phase (i.e., the sorbent); $A_{\alpha, v}^{\mathrm{o}}=1 /\left(M_{\alpha, v} \Gamma_{\mathrm{o}}\right)$ (in $\left.\mathrm{m}^{2} \mathrm{~g}^{-1}\right) ; M_{\alpha, v}$ is the molar mass of the sorbent; $x_{j}$ is a number of moles of $j$-th surface species; and $\phi_{\alpha, t}$ is a fraction of $A_{\alpha, v}$ related to $t$-th surface type. $\Xi_{j}=f\left(x_{j}, \Gamma_{\max }\right)$ stands for a surface activity term (SAT), - a special "concentration correction" term that replaces the balance constraint on the maximum number of surface sites available for the $j$-th species. SAT may also incorporate the activity coefficients responsible for any non-thermodynamic (lateral) interactions between surface species. The right-hand side of Eq. (1) connects the surface density fraction $\Gamma_{j} / \Gamma_{\mathrm{o}}$ to the molar quantities of the sorbent and the surface species; it can be derived according to the equations:

$$
\frac{\Gamma_{j}}{\Gamma_{\mathrm{o}}}=\frac{x_{j}}{\chi_{\alpha, t}^{\mathrm{o}}} ; \quad \chi_{\alpha, t}^{\mathrm{o}}=\phi_{\alpha, t} X_{\alpha, \mathrm{v}} M_{\alpha, \mathrm{v}} A_{\alpha, \mathrm{v}} \Gamma_{\mathrm{o}} ; \quad \Gamma_{\mathrm{o}}=\frac{1}{M_{\alpha, \mathrm{v}} A_{\alpha, \mathrm{v}}^{\mathrm{o}}},
$$

where $\chi_{\alpha, t}^{0}$ defines an expected mole quantity of surface species at reference density on $t$-th surface type on the $\alpha$-th sorbent. As seen from Eq. (2), usage of the "reference specific surface area" $A_{\alpha, v}^{o}$ is convenient to eliminate molar mass of the sorbent from Eq. (1). Substituting the latter into the definition of electrochemical potential, $\mu=\mu^{0}+$ $\ln a+C_{\mathrm{F}}\left(C_{\mathrm{F}}\right.$ is the Coulombic term) [21], one obtains an (electro)chemical potential of a $j$-th monodentately-bound surface species $[14,15]$ :

$$
\begin{aligned}
\mu_{j}= & \frac{g_{j, T}^{\mathrm{o}}}{R T}+\ln 55.5084+\ln \frac{A_{\alpha, \mathrm{v}}^{\mathrm{o}}}{\phi_{\alpha, t} A_{\alpha, \mathrm{v}}}+\ln \frac{x_{j}}{X_{\alpha, \mathrm{v}}}+\ln \Xi_{j} \\
& +\frac{F}{R T} z_{j} \Psi_{\alpha, t},
\end{aligned}
$$

where $z_{j}$ is the effective formula charge, $F=96485 \mathrm{C} \mathrm{mol}^{-1}$ is the Faraday's constant, $\Psi_{\alpha, t}$ is an electrostatic potential on $t$-th surface type (at EDL plane), $R=8.3145 \mathrm{~J} \mathrm{~K}^{-1} \mathrm{~mol}^{-1}$ is the universal gas constant, and $\ln (55.5084)$ converts from the molality concentration units, in which $g_{j, T}^{\mathrm{o}}$ is taken. The $g_{j, T}^{\mathrm{o}}$ stands for the standard partial molal Gibbs energy function of $j$-th surface species at temperature $T$ of interest. The sum of all terms on the right-hand side of Eq. (3) but the first one operationally defines activity of a surface species as a difference of relative chemical potentials: $\ln a_{j}=\mu_{j}-$ $\mu_{j}^{\mathrm{o}}$. Eq. (3), central in GEM implementation of SCMs, contains all necessary conversions from the state of interest to the standard/reference states, and fully reflects the "interfacial" nature of surface species. This equation is also helpful in determining equilibrium constants of surface species from their $G_{298}^{\mathrm{o}}$ values for usage in the LMA-based speciation algorithms.

\section{Activity-concentration relationships for surface species}

In the LMA SCMs, the total number of moles of reactive surface sites of $t$-th surface is set by the $N_{t, s}$ balance constraint [8]. For the multi-site-surface sorption models, several $N_{t, s}$ values must be a priori fixed as input data. However, in GEM SCMs, $N_{t, s}$ constraints can be avoided and replaced by the SAT $\Xi_{j}$, which suppresses the concentration of $j$-th surface complex when, upon increasing activity of the aqueous sorbate counterpart, the adsorbed density $\Gamma_{j}$ (in occupied sites per unit surface area) approaches a "geometrical limit" defined by the $\Gamma_{\max }$ parameter. $\Gamma_{\max }$ can either be taken the same for species competing on the $t$-th surface type ( $\Gamma_{t, \max }$ for competitive adsorption), or individually for certain species $\left(\Gamma_{j, t, \max }\right.$ for non-competitive adsorption).

It is important to realize that the reference (site) density $\Gamma_{\mathrm{o}}$, only used for normalisation of $g_{j, T}^{\mathrm{o}}$ and surface concentrations to the standard state, is not the same as individual $\left(\Gamma_{j, t, \max }\right)$ or common $\left(\Gamma_{t, \text { max }}\right)$ parameters. This distinction has not been done in the LMA SCMs, where the total site density parameter $\Gamma_{\mathrm{T}}$ (used in setting the $N_{t, s}$ constraint) is simultaneously a competitive maximum density $\Gamma_{\max }$ and a conditional reference site density $\Gamma_{\mathrm{C}}$ (ranging from 1 to 22 sites $\mathrm{nm}^{-2}$ ) to which the fitted values of the $2 \mathrm{p} K_{\mathrm{A}} \mathrm{SCM} K^{\text {int }}$ must refer. As follows from Eqs. (1-3), the values of $g_{j, T}^{o}$ (and also $a_{j}$ and $K^{\mathrm{int}}$ ), fitted at different $\Gamma_{\mathrm{C} 1} \neq \Gamma_{\mathrm{C} 2}$, are incompatible and must be scaled down to reference site density $\Gamma_{\mathrm{o}}$ before any comparison or correlation. Let $\Gamma_{\mathrm{o}}=q \cdot \Gamma_{\mathrm{C}}$, where $q \neq 1$. How the value of a conditional equilibrium surface complexation constant depends on the $q$ factor? For the activity of a single surface complex, the Brought to you by | Lib4RI Eawag-Empa Authenticated 
substitution of $\Gamma_{\mathrm{o}}$ by $q \cdot \Gamma_{\mathrm{C}}$ in Eq. (1) yields

$$
a_{j}^{(\mathrm{o})} q=a_{j}^{\mathrm{C}} .
$$

Thus, in the LMA expression for a $k$-th "surface complex exchange" reaction that does not contain the "surface solvent" $\equiv \mathrm{OH}^{\circ}$, the $q$ factors will divide out. For instance, the $\equiv \mathrm{OH}_{2}{ }^{+}=\equiv \mathrm{O}^{-}+2 \mathrm{H}^{+}(\mathrm{aq})$ reaction determines $\mathrm{pH}_{\mathrm{PPZC}}$ (pristine point of zero surface charge), with the LMA expression:

$$
K=\frac{a\left(\equiv \mathrm{O}^{-}\right) \cdot a^{2}\left(\mathrm{H}^{+}\right)}{a\left(\equiv \mathrm{OH}_{2}^{+}\right)}, \mathrm{p} K=2 \mathrm{pH}_{\mathrm{PPZC}}, \text { and } K_{k}^{(\mathrm{o})}=K_{k}^{\mathrm{C}} .
$$

Indeed, $\mathrm{pH}_{\mathrm{PPZC}}$ is a measurable quantity, independent of the site density parameter value.

However, the typically used $2 \mathrm{p} K$ surface complexation reactions like $\equiv \mathrm{OH}^{\circ}=\equiv \mathrm{O}^{-}+\mathrm{H}^{+}(\mathrm{aq})$ include "surface water solvent" (the neutral $\equiv \mathrm{OH}^{\circ}$ surface group), activity of which is constant [15]:

$$
\ln a\left(\equiv \mathrm{OH}^{\circ}\right)=\ln a\left(\mathrm{H}_{2} \mathrm{O}\right) \cdot \mathrm{const}+\ln 55.5084,
$$

where the activity of water-solvent $a\left(\mathrm{H}_{2} \mathrm{O}\right) \leq 1$ is taken in the mole-fraction scale, but activity of the $\equiv \mathrm{OH}^{\circ}$ group is expressed in the molal scale. In this case, $K_{k}^{(\mathrm{o})} q=K_{k}^{\mathrm{C}}$ and

$$
\log K_{k}^{(\mathrm{o})}=\log K_{k}^{\mathrm{C}}+\log \frac{\Gamma_{\mathrm{C}}}{\Gamma_{\mathrm{o}}} .
$$

The above analysis can be applied to any surface binding reaction to clarify how its equilibrium constant depends on the reference site density parameter. Eq. (7) can be used for the approximate conversion of the $K^{\text {int }}$ values (fitted with LMA codes at low surface coverages) into the standard-state $K^{(0)}$ constants with the uncertainty $<0.2 \mathrm{p} K$ units. The sign at the last term of Eq. (7) must be inverted if the $\equiv \mathrm{OH}^{\circ}$ species shifts to the right-hand side of the reaction.

The reference state of a surface complex - "infinitely low surface density at infinite dilution of the aqueous sorbate counterpart" (Sect. 2) - occurs simultaneously with the "full monolayer coverage at $\Gamma_{\mathrm{o}}$ " reference state of the "surface solvent" - the $\equiv \mathrm{OH}^{\circ}$ functional group. Upon increase in the activity of aqueous sorbate counterpart, both the concentration and the activity of the surface complex first increase proportionally to the aqueous sorbate concentration (linear adsorption region), consuming/eliminating the equivalent amount of the $\equiv \mathrm{OH}^{\circ}$ groups. When the maximum density $\Gamma_{j, t, \max }$ is approached closer, the activities of the sorbate and the surface complex both will continue to increase, while the concentration of surface-bound species becomes limited by the density of available sites - a maximum possible density of $j$-th species on $t$-th surface type $\Gamma_{j, t, \max }$. This kind of behavior is prescribed e.g. by the Langmuir isotherm [21]. It can be shown [15] that the Langmuir isotherm equation actually contains a "site-saturation correction factor"

$$
\Xi_{j}=\frac{\theta}{1-\theta} \text { where } \theta=\frac{\Gamma_{j}}{\Gamma_{j, t, \max }}, 0<\theta<1, \text { and } \Xi_{j} \geq 1 .
$$

Note that the fractional surface coverage $\theta$ is not the same as thermodynamic surface concentration $\Gamma_{\mathrm{j}} / \Gamma_{\mathrm{o}}$ (Eq. (1)). The difference between the surface density parameters $\Gamma_{\mathrm{o}}$ and $\Gamma_{j, t, \max }$ is that the former is part of the definition of standard state of surface species - a conventional constant value, while the latter is a mineral surface specific physical parameter, which can be fitted or determined from crystallographic or spectroscopic data. This explains why these two parameters are thermodynamically different (although in some cases they may be numerically equal); why thermodynamic concentration of a surface-bound species must be defined via $\Gamma_{\mathrm{o}}$ but not $\Gamma_{j, t, \max }$; and why the $\Gamma_{j, t, \max }$ parameter must go into the (non-thermodynamic) value of the site-saturation correction term, called a surface activity term (SAT) in order not to mix it with the "physical" activity coefficients.

When a sorbate binds to specific sites into a monodentate $j$-th surface complex and no other sorbates compete for these sites, a non-competitive SAT function [15] must be applied (see Eq. (8)):

$$
\ln \Xi_{j}^{(n)}=\left\{\begin{array}{l}
0, x_{j} \leq \frac{1}{2} \chi_{j, t, L} \\
\ln x_{j}-\ln \left(\chi_{j, t, L}-x_{j}\right)
\end{array},\right.
$$

where $\chi_{j, t, L}=\phi_{\alpha, t} A_{\alpha, v} X_{\alpha, v} M_{\alpha, v} \Gamma_{j, t, \max }$ is an expected maximum mole quantity of $j$-th surface complex on $t$-th surface type. The SAT Eq. (9) permits to assign separate maximum densities to reactive sites of different energy on the same surface type without introduction of $N_{t, s}$ balance constraints. Calculated between GEM iterations, Eq. (9) reproduces closely shape of Langmuir isotherms with linear part at the low coverage ( $\Xi$ is truncated to 1 at $\theta \leq 0.5$ ), bending asymptotically to $\Gamma_{j, t, \max }$ at high coverage.

If several sorbates compete for the same surface type sites then their total must not exceed the expected total maximum mole quantity $X_{\alpha, t, L}=\phi_{\alpha, t} A_{\alpha, v} X_{\alpha, v} M_{\alpha, v} \Gamma_{t, L, \max }$ for $t$-th surface type, defined using a common maximum density parameter $\Gamma_{t, L, \max }$. Mole quantity of each competing surface complex is then constrained by

$$
x_{j}<\chi_{t, L} \text { where } \chi_{t, L}=X_{\alpha, t, L}-\sum_{k \in l_{a}^{(r)}} x_{k}, j \in l_{\alpha} \backslash l_{\alpha, n} ; k \neq j,
$$

where $\chi_{t, L}$ is a number of moles of not-yet-consumed "surface solvent", and $l_{\alpha, n}$ stands for a set of non-reacted neutral $\equiv \mathrm{OH}^{\circ}$ groups, which need a special form of SAT correction [15] but may be excluded from the GEM model system because they do not influence the modelled proton- or ion adsorption curves. A competitive SAT function for monodentate binding follows from Eqs. $(9,10)$ :

$$
\ln \Xi_{j}^{(c)}=\left\{\begin{array}{l}
0, x_{j} \leq \frac{1}{2} \chi_{t, L} ; \\
\ln x_{j}-\ln \left(\chi_{t, L}-x_{j}\right)
\end{array} .\right.
$$

Eq. (11) is usually applied to the outer-sphere surface complexes at relatively high surface coverage, or to the cations bound to permanent-charge surfaces, e.g., on clay particles [22], expected to compete for the same surface sites of relatively large maximum total density $\Gamma_{t, L, \max }$, typically between 1 and 22 sites $\mathrm{nm}^{-2}$ (1.66 to $36.5 \mu \mathrm{mol} \mathrm{m}^{-2}$ ). At the same time, surface complexes compete with aqueous sorbates, as required by the total elemental mass balance in the chemical system and governed by the respective standard Gibbs energy values $g_{T}^{\mathrm{o}}$. On the other hand, specific Brought to you by | Lib4RI Eawag-Empa Authenticated 
inner-sphere binding of metal cations to "strong" sites of rather low density $\left(<0.3\right.$ sites $\left.\mathrm{nm}^{-2}\right)$ must be taken into account at low coverages and low dissolved metal concentrations $[9,23]$. In this case, the competition is rather difficult to demonstrate, so the "individual" SAT corrections (Eq. (9)) can be applied to all "strong" surface species that can be assigned to the same surface type.

Activity of any chemical species can be defined as

$$
\ln a_{j}=\mu_{j}-\frac{g_{j, T}^{\mathrm{o}}}{R T},
$$

where (electro)chemical potential $\mu_{j}$ depends mainly on the bulk composition of the whole aqueous electrolyte-sorbent system and on the species elemental stoichiometry. In other words, thermodynamic activity of a species measures a ratio of its current- to the standard/reference-state concentration in its phase at equilibrium [16]. Conversely, using Eq. (12) to re-arrange Eq. (3) yields

$$
\ln x_{j}=\ln a_{j}-\ln \Xi_{j}-C_{\mathrm{F}}+\ln \left(\frac{\phi_{\alpha, t} A_{\alpha, \mathrm{v}} X_{\alpha, \mathrm{v}}}{55.5084 A_{\alpha, \mathrm{v}}^{\mathrm{o}}}\right) .
$$

The rightmost term in Eq. (13) can be considered constant if the mole quantity of the sorbent $X_{\alpha, \mathrm{v}}$ and its molar mass are fixed. The SAT term $\ln \Xi_{j}$ is the only non-thermodynamic concentration correction term in the case of non-electrostatic site-binding model (NEM), where the Coulombic term $C_{\mathrm{F}}$ is ignored (set to zero). Away of zero-charge $\mathrm{pH}$ point $\left(\mathrm{pH}_{\mathrm{PZC}}\right)$, in the electrostatic SCMs, the $C_{\mathrm{F}}$ term would affect concentration of any charged surface complex even at low surface coverage, where no SAT contribution is expected. At high coverages, the SAT $\ln \Xi_{j}>0$ comes into play only when the $C_{\mathrm{F}}$ term is insufficient to suppress $j$-th charged surface complex below the $0.5 \cdot \Gamma_{t, L, \max }$ limit, or when $C_{\mathrm{F}}$ enhances concentrations of a surface complex charged opposite to that of the total surface charge and the potential $\Psi$. Thus, at a given activity $a_{j}$, the mole quantity and concentration of a neutral surface complex are affected by the SAT term only, while that of a charged surface species - by an interplay between SAT and Coulombic terms. Note that both $\Xi_{j}$ and $C_{\mathrm{F}}$ quantities are, actually, physical, non-thermodynamic correction factors, hence validity of thermodynamic treatment of SCMs presented here should not depend on the choice of (non)electrostatic EDL model. Standard partial molal thermodynamic properties of surface species of known elemental stoichiometry must not depend on that choice too. A huge literature (cf. [24]) exists about the surface charging behaviour and the details of the electrostatic phenomena on oxide surfaces - these to be accounted for in SAT and Coulombic terms.

\section{Elemental stoichiometry of the $\equiv \mathrm{OH}$ functional group and surface complexes}

The classic $2 \mathrm{p} K_{\mathrm{A}}$ SCMs - TLM, double layer model (DLM), or constant capacitance model (CCM) - all assume that oxide surfaces expose the neutral amphoteric $\equiv \mathrm{OH}^{\circ}$ functional groups which can react with the aqueous species via (de)protonation, exchange with anions, or binding of aqueous cations into the outer- or inner-sphere surface complexes $[20,25]$. In this framework, the standard partial molal properties (e.g., $\left.G_{298}^{\mathrm{o}}\right)$ of a surface complex can be calculated via the respective adsorption reaction stoichiometry and the thermodynamic equilibrium constant $K$, if the standardstate molal properties and the elemental stoichiometry of the $\equiv \mathrm{OH}^{\circ}$ group are known.

Elemental stoichiometry of the $\equiv \mathrm{OH}^{\circ}$ species, if viewed as a "surface solvent", must contain water, with an ambiguity whether to include the sorbent or not (e.g., $\left[\mathrm{TiO}_{1.5}\right] \mathrm{OH}^{\circ}$ versus $\mathrm{OH}^{\circ}$ ). To resolve this ambiguity, a cornerstone decision must be made before starting with compilation of a unified thermodynamic sorption database. Involvement of the sorbent atoms would make the standard molal properties of surface species dependent on the composition of the sorbent surface layer; consequently, these properties will be comparable over a single mineral surface type only.

Perhaps, this problem is more important for the GEM than for the LMA approach, because in the latter, the sorbent stoichiometry only identifies the $N_{t, s}$ balance constraint and, thus, is irrelevant. Besides, for some solid sorbents (solid solutions, clay minerals, aluminosilicates, and ion-exchange resins) it is difficult if not impossible to identify a fixed part of their stoichiometry to be assigned to the surface species. In view of these problems, our choice not to include stoichiometry of the sorbent into the elemental stoichiometry of surface species makes their standard partial molal properties comparable between different surfaces and minerals, as well as consistent with that of aqueous sorbates, solids and gases. Such "definite elemental stoichiometry" monodentate surface species will be designated with a '>' symbol, which simply shows that the component belongs to the surface of a sorption phase; the ' $\equiv$ ' symbol will be retained for the "generic" surface-bound species. The $\mathrm{O}_{0.5} \mathrm{H}^{\circ}$ formula provides the simplest stoichiometry of $>\mathrm{O}_{0.5} \mathrm{H}^{\circ}$ functional group [14, 15]:

$$
0.5 \mathrm{H}_{2} \mathrm{O}_{\text {aq }}=>\mathrm{O}_{0.5} \mathrm{H}^{\mathrm{o}} ; \quad K_{n} .
$$

From the determined value $G_{298}^{\mathrm{o}}\left(>\mathrm{O}_{0.5} \mathrm{H}^{\mathrm{o}}\right)=-128.548 \mathrm{~kJ}$. $\mathrm{mol}^{-1}$, it follows that $\Delta G_{n, 298}^{\mathrm{o}}=-9.957 \mathrm{~kJ} \mathrm{~mol}^{-1}$, and $\log K_{n}=1.74436$ at any $T$ [14]. Two $>\mathrm{O}_{0.5} \mathrm{H}^{\circ}$ species can be viewed as one $\mathrm{H}_{2} \mathrm{O}$ molecule kept at two primary sites of $\Gamma_{\mathrm{o}}$ density on any solid (hydr)oxide surface. Further, the reaction

$$
>\mathrm{O}_{0.5} \mathrm{H}_{2}{ }^{+}=>\mathrm{O}_{0.5} \mathrm{H}^{\mathrm{o}}+\mathrm{H}_{\mathrm{aq}}^{+} ; \quad K_{\mathrm{A} 1}
$$

describes transfer of a "surface hydronium" $\left(\mathrm{O}_{0.5} \mathrm{H}_{2}{ }^{+}\right)$into the aqueous proton $\left(\mathrm{H}_{\mathrm{aq}}^{+}\right)$. Reaction

$$
>\mathrm{O}_{0.5} \mathrm{H}^{\mathrm{o}}=>\mathrm{O}_{0.5}{ }^{-}+\mathrm{H}_{\mathrm{aq}}^{+} ; \quad K_{\mathrm{A} 2}
$$

can be considered as a dissociation of "surface solvent" $\left(\mathrm{O}_{0.5} \mathrm{H}^{\circ}\right)$ into a "surface hydroxyl" $\left(\mathrm{O}_{0.5}{ }^{-}\right)$and aqueous proton. The standard molal properties and stoichiometry of $>\mathrm{O}_{0.5} \mathrm{H}^{\circ}$, as such, imply no specific features of a particular mineral surface such as geometry, density and charges of the broken bonds. Rather, the $>\mathrm{O}_{0.5} \mathrm{H}^{\circ}$ species is a conventional thermodynamic entity needed to connect the standard partial molal properties of surface complexes to that of chemical elements, aqueous ions, minerals and gases. This does not imply that chemical nature of the mineral surface is totally neglected: in GEM approach, all chemical specificity Brought to you by | Lib4RI Eawag-Empa 
is assigned to stoichiometries and standard partial molal properties of the surface complexes and their $\Gamma_{\max }$ parameters, rather than to the properties of the $>\mathrm{O}_{0.5} \mathrm{H}^{\circ}$ groups that comprise a "reference point" common to all surfaces. For instance, a mineral surface-specific $G^{\mathrm{o}}\left(>\mathrm{O}_{0.5}{ }^{-}\right)$value can be found from the common $G^{\circ}\left(>\mathrm{O}_{0.5} \mathrm{H}^{\circ}\right)$ value and the known $K_{\mathrm{A} 2}$ value (using $\Delta G_{\mathrm{r}}^{\mathrm{o}}=-2.303 \log K$ ), or, vice versa, $K_{\mathrm{A} 2}$ can be calculated from $G^{\circ}\left(>\mathrm{O}_{0.5} \mathrm{H}^{\circ}\right)$ and known (fitted or predicted) value of $G^{\circ}\left(>\mathrm{O}_{0.5}{ }^{-}\right)$using Eq. (16) at any $T$. To summarize, the $G^{\circ}\left(>\mathrm{O}_{0.5} \mathrm{H}^{\circ}\right)$ value tells nothing specific about sorbent surfaces and sites, while the $G^{\circ}(>$ $\mathrm{O}_{0.5}{ }^{-}$) value describes how basic is the surface of a particular mineral and, together with the $G^{\mathrm{o}}\left(>\mathrm{O}_{0.5} \mathrm{H}_{2}{ }^{+}\right)$value, determines $\mathrm{pH}_{\mathrm{PPZC}}$ and the surface "amphoteric strength" $\left(\Delta \mathrm{p} K_{\mathrm{A}}\right)$, scaled down to the standard state.

A major weakness of $2 \mathrm{p} K_{\mathrm{A}} \mathrm{SCMs}$ is that involvement of the $\equiv \mathrm{OH}^{\circ}$ (or $>\mathrm{O}_{0.5} \mathrm{H}^{\circ}$ ) species, activity of which is constant as long as liquid $\mathrm{H}_{2} \mathrm{O}$ is present in the system, makes the LMA-fitted $K^{\text {int }}$ values highly sensitive to the site density parameter $\left(\Gamma_{\mathrm{C}}=\Gamma_{\mathrm{T}}=\Gamma_{\max }\right)$ and chosen value of $\Delta \mathrm{p} K_{\mathrm{A}}$. The smaller are these two parameters, the stronger are the SAT increments into LMA expressions for the reactions like Eqs. $(15,16)$ at higher surface coverages. Conversely, the large $\Delta \mathrm{p} K_{\mathrm{A}}$ and $\Gamma_{\mathrm{C}}$ parameters (as usually selected in TLM on the background of rather strong Coulombic corrections) favor nearly-unity SAT ratios in a very wide interval of surface coverage [15]. Note, that in GEM SCMs, the $>\mathrm{O}_{0.5} \mathrm{H}^{\circ}$ species does not affect the fits to titration data at all and may be dropped from the model system. Hence, the GEM SCMs work, in fact, similar to the $1 \mathrm{p} K_{\mathrm{A}}$ LMA SCMs [14].

In the mathematical formulation of GEM SCMs (Eqs. $(3,13)$ ), the standard partial molal Gibbs energy of a surface species $g_{j, T}^{\circ}$ is separated from the Coulombic term (i.e. surface charge-potential relationships), the normalization to sorbent surface area, and the SAT term $\Xi_{j}$ (i.e. impact of the density saturation, set by the mineral surface-specific $\Gamma_{j, \max }$ parameter). Due to this, fitting of the adsorption isotherm- or potentiometric titration data yields directly the $G^{\circ}$ values for surface complexes for the chosen elemental stoichiometry; then, thermodynamic $\log K$ values of adsorption reactions can be calculated. An obvious criterion of quality of GEM SCM fits is the minimum of constraints imposed in addition to standard-state thermodynamic data [15]. Hence, the fits should be considered optimal when they can describe the widest region of the adsorption data without invocation of the SAT corrections and adjustment of the additional $\Gamma_{\max }$ parameters, unless independent (e.g. crystallographic) evidence about maximum available site densities is provided.

There is no reason why thermodynamic treatment of surface complexation (outlined above) may not be implemented also into the (modified) LMA codes for speciation modelling. Conversely, it must be possible to reproduce the existing LMA SCM fits in the GEM SCM implementation. In this case, one needs: (1) to convert intrinsic $K^{\text {int }}$ values of the adsorption reactions into thermodynamic equilibrium constants $K$ using Eq. (7); (2) to define appropriate elemental stoichiometries of surface species and allocate them to surface types; (3) to calculate standard $G^{\circ}$ values of surface complexes. All assumptions of the LMA-based SCM will be inherited by the GEM implementation.

\section{Adsorption of U(VI) on $\mathrm{SiO}_{2}$ phases: thermodynamic data acquisition strategies}

Mobility of $\mathrm{U}(\mathrm{VI})$ at low total concentrations in the waterrock systems depends on its tendency to adsorb to solid substrates in favour of strong aqueous complexes that are weakly adsorbed. This motivated extensive studies of uranyl sorption onto quartz, amorphous silica, ferrihydrite, montmorillonite and other minerals [2,26-31], as well as on bulk rock assemblages [2].

In recent publications [2,30], several experimental $\mathrm{pH}-$ edge data sets for U(VI) adsorption on quartz and other minerals are described, which were measured at ambient conditions at various $\mathrm{pH}$, different solid-liquid ratios, total concentrations of $\mathrm{U}(\mathrm{VI})$ and complexing ligands, and ionic strength (usually $\mathrm{NaNO}_{3}$ ). These data were modelled with the multi-site SCMs [2], in some cases backed up by the EXAFS and FTIR studies [2,26] confirming existence of the bidentate ternary complexes such as $\mathrm{Fe}<{ }_{\mathrm{O}}^{\mathrm{O}}>\mathrm{UO}_{2}\left(\mathrm{CO}_{3}\right)_{x}{ }^{-2 x}$ where the uranyl ion is coordinated equatorially to the $[\mathrm{Fe}, \mathrm{O}]$ octahedra edges on the oxide surface. On silica surfaces, existence of bidentate equatorially-coordinated uranyl (hydroxo)complexes is supposed on the basis of EXAFS studies [32,33].

In this contribution, using literature data for U(IV) adsorption on $\mathrm{SiO}_{2}$ phases at ambient conditions $[2,29,30$, $34,35]$ - a system small enough to be easily observable, - two possible approaches will be illustrated in a step-bystep construction of a subset of the unified thermodynamic database for uranium sorption on oxide-water interfaces. The database can be further extended for other mineral sorbents (e.g. $\mathrm{TiO}_{2}, \mathrm{Al}$ and $\mathrm{Fe}$ (hydr)oxides, clay minerals) and, eventually, for different adsorbates (aqueous cations and anions) using either of two approaches with GEM or LMA codes wherever appropriate. The simplest, "top-down" approach is to recast surface species stoichiometry and $K^{\text {int }}$ from an already developed LMA SCM into standard molal $G_{298}^{\mathrm{o}}$ values and check them in GEM SCM runs, while making no attempts to justify selection of the surface species stoichiometry or the EDL model of the mineral-water interface. The alternative, "bottom-up" approach is to select the appropriate EDL model and the feasible stoichiometries of metal surface complexes on the basis of the available micro/spectroscopy studies, followed by direct fitting of $G_{298}^{\mathrm{o}}$ values in GEM SCM runs at different $\mathrm{pH}$, surface coverages, samples and electrolytes. Thus obtained thermodynamic data (with related $\Gamma_{\max }$ parameters, if needed) are then converted into intrinsic adsorption constants at a given $\Gamma_{\mathrm{C}}$ parameter value for usage in LMA codes.

For GEM implementation, the $G_{298}^{\circ}$ values for aqueous species, quartz, and uranium minerals were taken from the latest Nagra/PSI database [36] and ported into GEMS-PSI code format using [37,38] (Thoenen and Kulik, in preparation), together with the Davies equation for aqueous activity coefficients (cf. [39]) to construct the system in a stoichiometry basis U-Na-Si-C-F-N-Nit-O-H-charge. Equilibrium constants for uranium aqueous species and minerals [36] are close to that used by Davis et al. (Table 2-1 in [2]) who discussed the $\mathrm{pH}$-dependent aqueous speciation of U(VI) and solubility of uranyl hydroxides in presence of $\mathrm{CO}_{3}{ }^{-2}, \mathrm{~F}^{-}$and $\mathrm{PO}_{4}{ }^{-3}$ ligands. However, the $\mathrm{UO}_{2} \mathrm{SiO}(\mathrm{OH})_{3}{ }^{+}$ 
aqueous complex was excluded on the basis of intolerable uncertainty, as recommended in [36]. The GEM model titrations were all computed using $\mathrm{NaNO}_{3}$ as a background electrolyte and the atmospheric nitrogen (Nit) decoupled from the nitrate nitrogen aqueous species. Batch runs of $\mathrm{pH}$ steps were simulated in the "Process" mode of GEM-Selektor by replacing equivalent parts of added $\mathrm{NaNO}_{3}$ with either $\mathrm{HNO}_{3}$ or $\mathrm{NaOH}$ to adjust $\mathrm{pH}$ but maintain constant ionic strength (usually 0.1 or $0.01 \mathrm{M}$ ).

\section{Conversion of the LMA NEM for the U(VI)-quartz system ("top-down" approach)}

\subsection{The U(VI)-crushed quartz system}

The initial system contained $0.1 \mathrm{~mol} \mathrm{NaNO}_{3}, 994 \mathrm{~g} \mathrm{H}_{2} \mathrm{O}$, $100.01 \mathrm{~g} \mathrm{SiO}_{2}$ and $10^{-6} \mathrm{~mol} \mathrm{UO}_{3}$ plus $30 \mathrm{~kg}$ of "dry model air" to maintain $\log \left(p_{\mathrm{CO}_{2}}\right)=-3.5 \pm 0.05$ bar at $T=25^{\circ} \mathrm{C}$ and $P=1$ bar. Aqueous electrolyte, gas mixture, rutherfordine $\mathrm{UO}_{2} \mathrm{CO}_{3}$, schoepite $\mathrm{UO}_{3} \cdot 2\left(\mathrm{H}_{2} \mathrm{O}\right)$, solid $\mathrm{UO}_{2}, \mathrm{USiO}_{4}$, and the uranyl-quartz sorption phase were included (uranium minerals were undersaturated in all model runs). The sorption phase was made of a sorbent $\left(\alpha\right.$-quartz $\left.\mathrm{SiO}_{2}\right)$ with $A_{q, \mathrm{v}}=0.33 \mathrm{~m}^{2} \mathrm{~g}^{-1} ;>\mathrm{O}_{0.5} \mathrm{H}^{\circ}$ species (reaction 14; taken at reference density $\Gamma^{\circ}$ ); and monodentate $\mathrm{U}(\mathrm{VI})$ surface complexes according to the NEM B4 of Davis and Kohler (Table 13-1 in [2]). Elemental stoichiometries of the uranyl surface complexes were constructed from the reactions:

$$
\begin{aligned}
& 1>\mathrm{O}_{0.5} \mathrm{H}^{\mathrm{o}}+\mathrm{UO}_{2}{ }^{+2}+\mathrm{H}_{2} \mathrm{O}=1>\mathrm{O}_{0.5} \mathrm{UO}_{2} \mathrm{OH}^{\mathrm{o}}+2 \mathrm{H}^{+},\left(1>\mathrm{OUO}_{2} \mathrm{OH}^{\circ}\right), \\
& 2>\mathrm{O}_{0.5} \mathrm{H}^{\mathrm{o}}+\mathrm{UO}_{2}{ }^{+2}+\mathrm{H}_{2} \mathrm{O}=2>\mathrm{O}_{0.5} \mathrm{UO}_{2} \mathrm{OH}^{\mathrm{o}}+2 \mathrm{H}^{+}, \\
&\left(2>\mathrm{OUO}_{2} \mathrm{OH}^{\mathrm{o}}\right), \\
& 1>\mathrm{O}_{0.5} \mathrm{H}^{\mathrm{o}}+\mathrm{UO}_{2}{ }^{+2}+\mathrm{CO}_{2}{ }^{\circ}+ \mathrm{H}_{2} \mathrm{O}= \\
& 1>\mathrm{O}_{0.5} \mathrm{UO}_{2} \mathrm{CO}_{3}^{-}+3 \mathrm{H}^{+}, \quad\left(1>\mathrm{OUO}_{2} \mathrm{CO}_{3}{ }^{-}\right) .
\end{aligned}
$$

Here, 1 and 2 assign to hypothetical site types, constrained in the original B4 model to 1.06056 and $0.01944 \mu \mathrm{mol} \mathrm{m}^{-2}$, respectively (at total $\Gamma_{\mathrm{T}}=1.08 \mu \mathrm{mol} \mathrm{m}^{-2}$ ), probably using two different balance constraints. In GEM NEM, one surface type was assumed for the whole quarts surface; the above site densities were used in competitive $\Gamma_{\max , 1}$ and individual $\Gamma_{\max , 2}$ SAT corrections.

Values of $\log K^{\text {int }}$ (Model B4) of three U(VI) surface complexes were first converted to $\log K$ using Eq. (7) and then into $G_{298}^{\mathrm{o}}$ using $G_{298}^{\mathrm{o}}$ values of other species (Appendix) involved in reactions (17) to (19) and (14) (Table 1). Note that the $\log K^{\text {int }}$ to $\log K$ conversion term for the site 1
$(-1.2755)$ is much weaker than that for the site 2 of low density (-3.0123). Experimental titration data (adsorbed fraction of $\mathrm{U}(\mathrm{VI}), \% \mathrm{U}_{\text {ads }}$ ) were digitised from figures in [2]. Goodness of GEM fits was estimated graphically, no formal SOS/DF criteria like that in FITEQL3 [4] were applied.

Already the first GEM NEM runs at $10^{-6} \mathrm{M}$ total $\mathrm{U}$ resulted in quite good fits (Fig. 1a). Sensitivity calculations
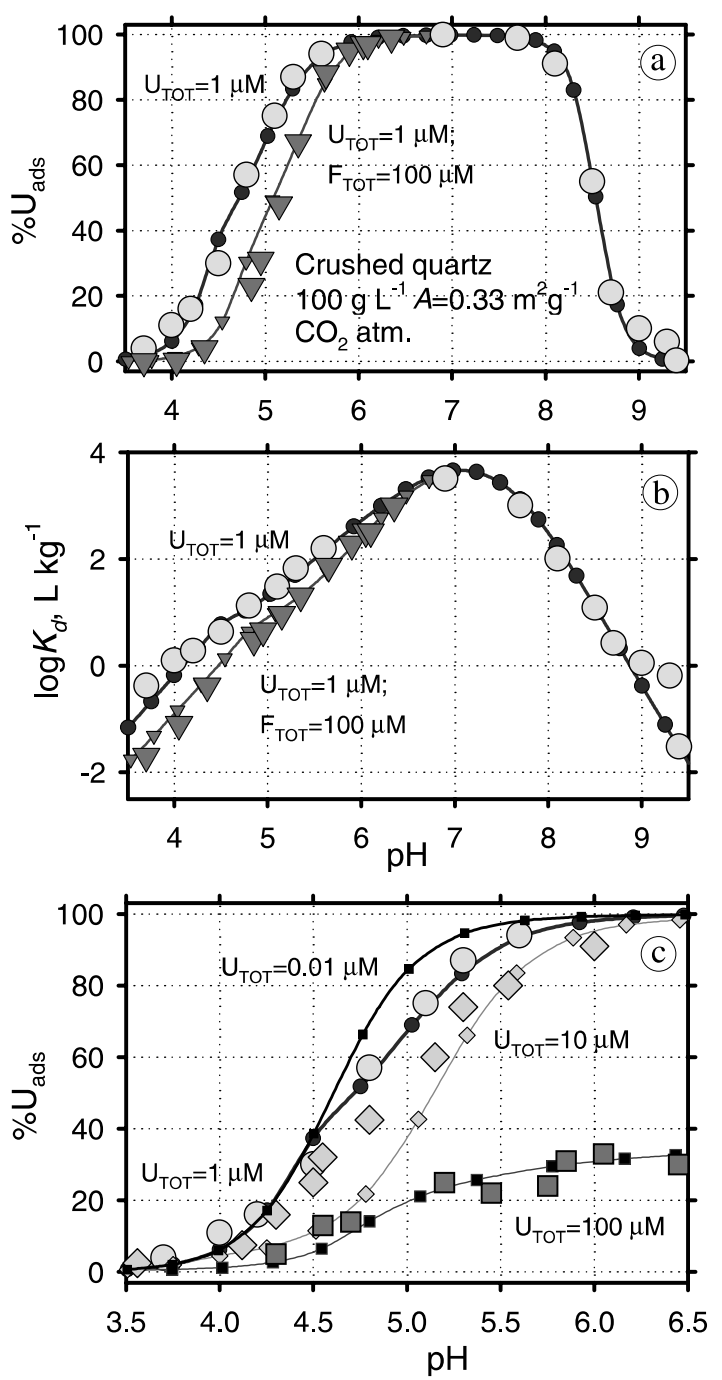

Fig. 1. Adsorption of $\mathrm{U}(\mathrm{VI})$ on quartz under ambient air $\left(\log p_{\mathrm{CO}_{2}}=\right.$ $-3.5 \pm 0.05)$ as function of $\mathrm{pH}$ in absence (circles) and presence of $10^{-4} \mathrm{M} \mathrm{NaF}$ (triangles), modeled with GEM NEM, Table 1 (large scattered symbols: experimental data [2]). (a): represented as percentage of total adsorbed uranium $\% \mathrm{U}_{\text {ads }} ;(\mathbf{b})$ : converted into $\log K \mathrm{~d}$ scale using Eq. (20); (c): modeled $\% \mathrm{U}_{\text {ads }}$ curves at different total U(VI) concentrations versus experimental data [2] at $10^{-6}, 10^{-5}$ and $10^{-4} \mathrm{M}$ total uranium.
Table 1. Standard-state data for the NEM SCM of the U(VI)-quartz system (1 bar $\left.25^{\circ} \mathrm{C}\right)$.

\begin{tabular}{lccccccc}
\hline $\begin{array}{l}\text { Species } \\
\text { name }\end{array}$ & Reaction & $\begin{array}{c}\log K^{\mathrm{int}} \\
\text { (init) }\end{array}$ & $\begin{array}{c}\Gamma_{\mathrm{C}}{ }^{a} \\
\mu \mathrm{mol} \mathrm{m}{ }^{-2}\end{array}$ & $\begin{array}{c}\log K \\
\text { converted }\end{array}$ & $\begin{array}{c}G_{298}^{\mathrm{o}} \\
\text { converted } \\
\mathrm{kJ} \mathrm{mol}^{-1}\end{array}$ & $\begin{array}{c}\Gamma_{\text {max }} \\
\text { sites nm }\end{array}$
\end{tabular}

a: from [2], Table 13-1, model B4;

b: uncertainty estimated from GEM NEM fits;

c: for the non-competitive SAT. 
pointed out that the fits remain satisfactory when $G_{298}^{\mathrm{o}}$ values of the U(VI) surface species on site 1 are varied within $\pm 1.713 \mathrm{~kJ} \mathrm{~mol}^{-1}( \pm 0.3 \log K$ unit) range, taken as an uncertainty estimate (Table 1 ). The NEM results can be readily converted into the "model $K_{\mathrm{d}}$ " plots if a ratio $\frac{V}{M}$ of the aqueous phase volume $V_{\mathrm{aq}}(1 \mathrm{~L})$ to the sorbent mass $M_{\mathrm{qtz}}(0.1 \mathrm{~kg})$ is known:

$$
K_{\mathrm{d}}=\frac{\mathrm{U}_{\mathrm{ads}}}{M_{\mathrm{qtz}}} \cdot \frac{V_{\mathrm{aq}}}{\mathrm{U}_{\mathrm{aq}}} \approx \frac{\% \mathrm{U}_{\mathrm{ads}}}{100-\% \mathrm{U}_{\mathrm{ads}}} \cdot \frac{V}{M} \quad\left(\text { in } \mathrm{L} \mathrm{kg}^{-1}\right) .
$$

This conversion (Fig. 1b) shows that the "smart" $K_{\mathrm{d}}$ values, generated from five GEM NEM parameters (Table 1) and the aqueous thermodynamic data, can vary over $5-6$ orders of magnitude.

As shown on Fig. 1c, the two-site NEM of Davis and Kohler [2], directly reproduced in GEM technique, provides
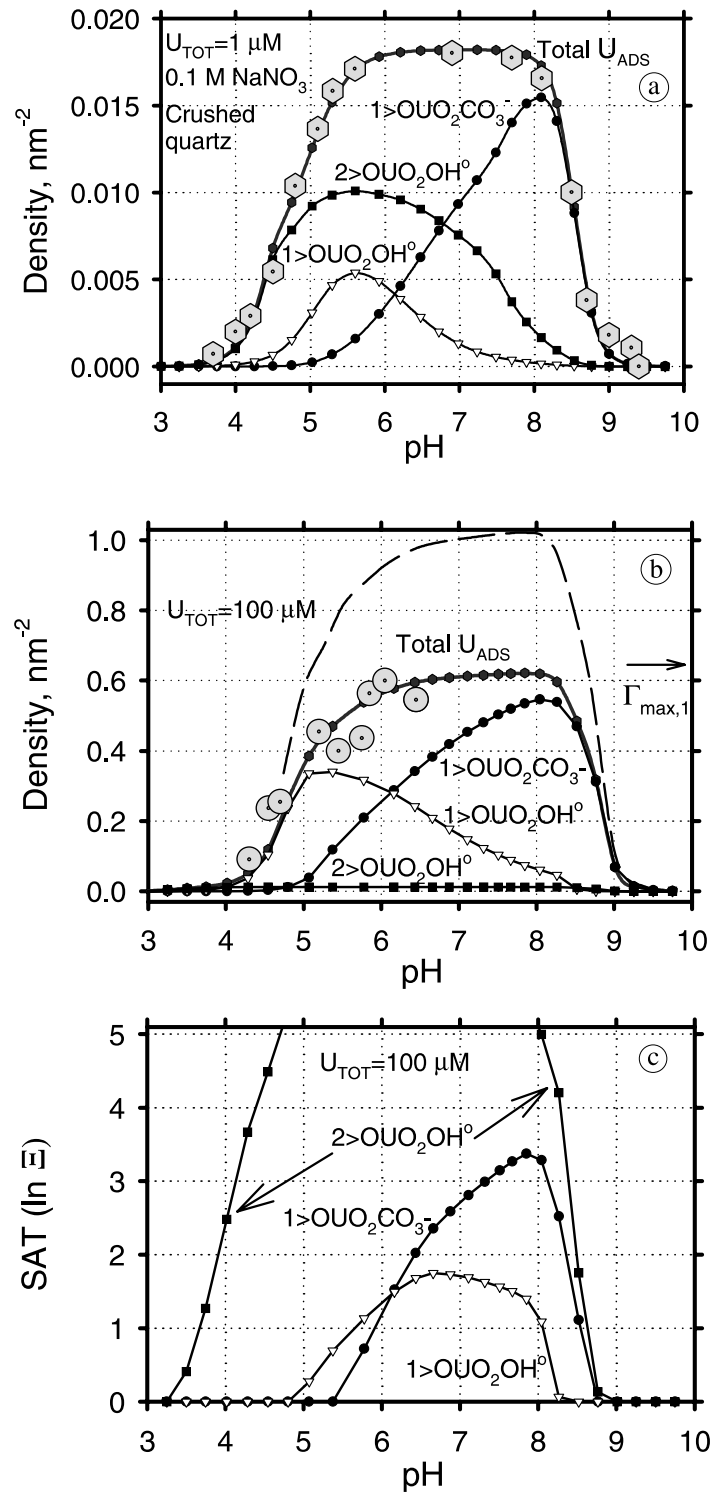

Fig. 2. GEM NEM fits for U(VI) adsorption on quartz as function of $\mathrm{pH}$, shown in the site-density scale (large symbols correspond to converted experimental data [2]). (a): surface speciation at $10^{-6} \mathrm{M}$ total uranium; (b): surface speciation at $10^{-4} \mathrm{M}$ total uranium, dashed line shows the total adsorbed U(VI) density at $\Gamma_{\text {max }, 1}=1.06$ sites nm$^{-2}$; (c): variation of SAT correction values for the $10^{-4} \mathrm{M}$ total uranium run above, competitive SAT at $\Gamma_{\text {max }, 1}=0.64$ sites nm$^{-2}$ for site 1 surface complexes, and individual SAT at $\Gamma_{\max , 2}=0.012$ sites nm $^{-2}$. a reasonably good description of $\mathrm{U}(\mathrm{VI})$ adsorption $\mathrm{pH}$ steps on crushed quartz in a wide range of $\mathrm{U}(\mathrm{VI})$ total concentrations. As seen from Fig. 2a, densities of the surface complexes on site 1 are far below the $\Gamma_{\max , 1}$ constraint $\left(0.64 \mathrm{~nm}^{-2}\right)$ and do not require SAT corrections, whereas density of the $2>\mathrm{OUO}_{2} \mathrm{OH}^{\circ}$ species is approaching the $\Gamma_{\max , 2}$ constraint $\left(0.012 \mathrm{~nm}^{-2}\right)$ under the individual SAT $\Xi>1$. At $10^{-8} \mathrm{M}$ total uranium $\left(\mathrm{U}_{\text {Tот }}\right)$, the latter correction also does not work, hence a difference between the curves for $1 \times 10^{-6} \mathrm{M}$ and $1 \times 10^{-8} \mathrm{M} \mathrm{U}_{\text {TOт }}$ on Fig. 1c. However, at higher $\mathrm{U}_{\text {TOT }}$, the NEM becomes quite sensitive to $\operatorname{SAT}\left(\Gamma_{\max , 1}\right)$ corrections; Fig. $2 \mathrm{~b}$ shows the surface speciation and fit at $\Gamma_{\max , 1}=0.64 \mathrm{~nm}^{-1}$ in comparison to the run at $\Gamma_{\max , 1}=1.06 \mathrm{~nm}^{-1}$. Fig. $2 \mathrm{c}$ shows the non-linear SAT curves that reach rather large values for all three surface species at high uranyl surface coverages, where $\Gamma_{\max }$ become important fitting parameters.

\subsection{The U(VI)-amorphous silica system}

To what extent $\log K$ and $G_{298}^{\mathrm{o}}$ values listed in Table 1 can be applied to model experimental pH steps of U(VI) adsorption onto other $\mathrm{SiO}_{2}$ solids? Fortunately, such data (measured in $\mathrm{NaNO}_{3}$ or $\mathrm{NaClO}_{4}$ electrolytes at ambient conditions) exist in literature for the synthetic amorphous silica $\mathrm{SiO}_{2}$, am $[29,31,34,35]$. Some of these data were described using electrostatic SCMs (CCM, TLM, and DLM), each with different stoichiometries of surface complexes, not directly inter-comparable with the above-discussed NEM for uranyl sorption on crushed quartz.

The GEM system formulation described in Sect. 6.1 has been modified by replacing the sorbent ( $\alpha$-quartz) by silica $\mathrm{SiO}_{2}$, am with a solubility product $\log K=-2.7$ ([39] in $\mathrm{SiO}_{2}, \mathrm{am}=\mathrm{SiO}_{2}{ }^{\circ}$, aq reaction) and high specific surface area (hundreds $\mathrm{m}^{2} \mathrm{~g}^{-1}$ ) yielding the total surface much greater than that of $100 \mathrm{~g} \mathrm{~L}^{-1}$ of crushed quartz [2]. The rest of system formulation remained intact.

To model titration data of Turner et al. [34] in $\mathrm{CO}_{2}$ free system, $0.25 \mathrm{~g} \mathrm{SiO}_{2}$ was added (to obtain $0.13 \mathrm{~g} \mathrm{~L}^{-1}$ of $\mathrm{SiO}_{2}$, am sorbent with $A=183 \mathrm{~m}^{2} \mathrm{~g}^{-1}$ at $\mathrm{pH}=6$ ), the air was replaced by $10 \mathrm{~mol}$ of (decoupled) nitrogen with $0.001 \mathrm{~mol}$ of oxygen, the total $\mathrm{UO}_{3}$ addition was $8.5 \mu \mathrm{mol}$, and $0.1 \mathrm{M} \mathrm{NaNO}_{3}$ was added instead of $\mathrm{NaClO}_{4}$ (silica surfaces are not significantly protonated, uranyl-nitrate aquocomplexes are weak, so this replacement is unlikely to influence the SCM fits). Values of $\mathrm{pH}$ in the range 3 to 8 were adjusted by adding $\mathrm{HNO}_{3}$ or $\mathrm{NaOH}$. Results of the first GEM batch run are shown on Fig. 3a (dashed line); the adsorbed uranyl fraction $\left(\% \mathrm{U}_{\text {ads }}\right)$ is clearly under-predicted. A possible improvement would be to adjust the $G_{298}^{\mathrm{o}}$ value of $1>\mathrm{UO}_{2} \mathrm{OH}^{\circ}$ species by adding $-2.85 \mathrm{~kJ} \mathrm{~mol}^{-1}$ (i.e. 0.5 $\log K$ unit stronger), see Fig. 3a (dotted line). Alternatively, even a better (and more justified) fit can be obtained supposing that the $\mathrm{SiO}_{2}$, am surface has a density of type 2 sites greater than the quartz surface. Indeed, a 10 times increase in $\Gamma_{\max , 2}$ constraint (to $0.12 \mathrm{~nm}^{-2}$ ) results in a good fit (solid line with diamonds on Fig. 3a), without any adjustment of the standard thermodynamic data (Table 1) initially obtained for the quartz- $\mathrm{UO}_{2}$ system.

To model data of Gabriel et al. [29], the excess air was included, the $\mathrm{NaNO}_{3}$ addition was set to $0.01 \mathrm{M}$, and the Brought to you by | Lib4RI Eawag-Empa 

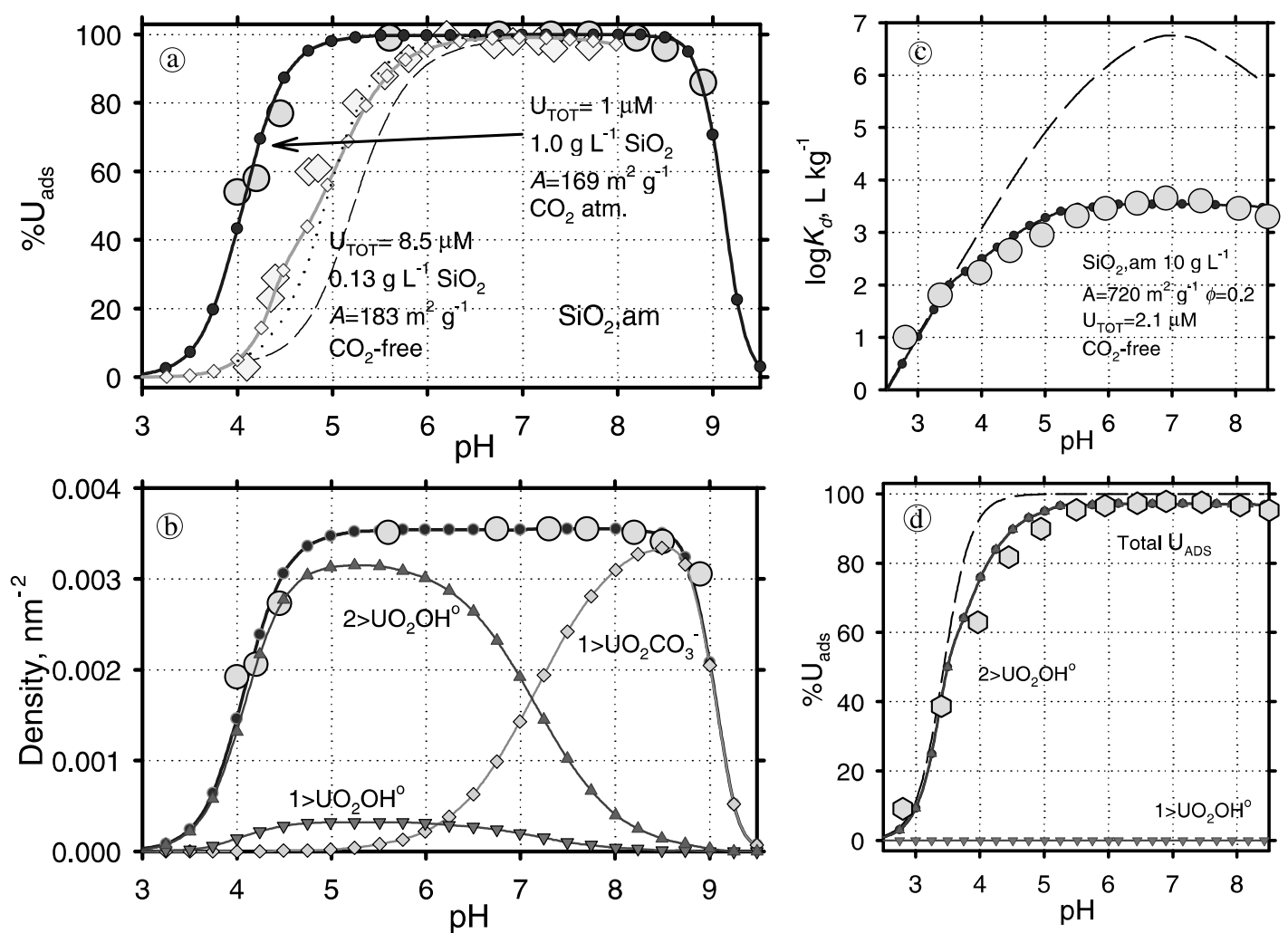

Fig. 3. GEM NEM fits for U(VI) adsorption on amorphous silica as function of pH at ambient conditions. (a): fraction of total adsorbed U(VI), experimental data: large circles [29], large diamonds [34], see text for explanations; (b) surface speciation for the system with experimental data [29];

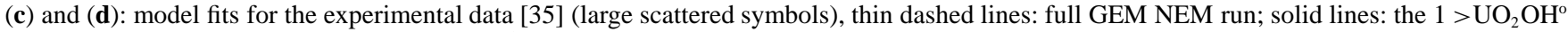
species disabled and $\Gamma_{\max , 2}=0.00087$ sites nm$^{-2}$.

total $\mathrm{UO}_{3}$ addition - to $1 \times 10^{-6}$ mol. $1.013 \mathrm{~g} \mathrm{~L}^{-1} \mathrm{SiO}_{2}$ was added (to have at equilibrium $c a .1 \mathrm{~g} \mathrm{~L}^{-1}$ of the sorbent with specific surface area $A=169 \mathrm{~m}^{2} \mathrm{~g}^{-1}$ ). A GEM NEM batch titration run with thermodynamic data from Table 1 immediately gave a good fit (line with dark circles on Fig. 3a), indicating that surface of the non-porous "Degussa Aerosil" silica particles used in experiments behaves similar to that of crushed quartz with respect to U(VI) adsorption. This fit, re-plotted in a surface density scale (Fig. 3b), shows that the adsorption densities of $\mathrm{U}(\mathrm{VI})$ on huge surface of $\mathrm{SiO}_{2}$, am are so small $\left(<0.0036\right.$ sites $\left.\mathrm{nm}^{-2}\right)$ that even the stronger $2>\mathrm{O}_{0.5} \mathrm{UO}_{2} \mathrm{OH}^{\circ}$ complex, dominant at $\mathrm{pH} 3$ to 7 , does not require any SAT corrections (i.e. it remains in the "linear adsorption" region). The $1>\mathrm{O}_{0.5} \mathrm{UO}_{2} \mathrm{CO}_{3}{ }^{-}$surface complex makes a dominant contribution at $\mathrm{pH} 7$ to 9.5 .

However, such a surface speciation pattern (with the simplest postulated stoichiometries of monodentate U(VI) surface species selected on a goodness-of-fit basis, see [2], pp. 145-150) is not quite compatible with the in situ observations [29, 31]. An alternative GEM TLM, developed using the in situ determined stoichiometries of surface complexes and XAFS results, is described below (Sect. 7.1).

To model the closed-system $\mathrm{CO}_{2}$-free titration data of Lieser et al. [35], the air addition was removed, $\mathrm{NaNO}_{3}$ addition was set to $10^{-5} \mathrm{M}$, and total $\mathrm{UO}_{3}$ addition was $2.1 \times 10^{-6}$ M. $10 \mathrm{~g} \mathrm{~L}^{-1}$ of $\mathrm{SiO}_{2}$ sorbent was present with a reported (tremendous) $720 \mathrm{~m}^{2} \mathrm{~g}^{-1}$ specific surface area. In batch GEM calculations, $\mathrm{pH}$ in the range 2.5 to 8.5 was adjusted by adding $\mathrm{HNO}_{3}$ or $\mathrm{NaOH}$. Results are plotted on Fig. $3 \mathrm{c}$ in the $K_{\mathrm{d}}$ (original experimental data) and on Fig. 3d in the adsorbed fraction $\left(\% \mathrm{U}_{\text {ads }}\right)$ scales. Conversion of $K_{\mathrm{d}}$ into adsorbed fractions is obtained by re-arranging Eq. (20):

$$
\% \mathrm{U}_{\mathrm{ads}}=100 \cdot \frac{K_{\mathrm{d}}}{K_{\mathrm{d}}+\frac{V}{M}}=100 \cdot\left(1+\frac{V}{M} \cdot K_{\mathrm{d}}^{-1}\right)^{-1} .
$$

In this system, $V / M \approx 100 \mathrm{~L} \mathrm{~kg}^{-1}$. Attempts to run the GEM NEM with $A=720 \mathrm{~m}^{2} \mathrm{~g}^{-1}$ failed because they overpredicted experimental $K_{\mathrm{d}}$ values by 1 to 6 orders of magnitude in the whole $\mathrm{pH}$ interval, perhaps, as a consequence of highly heterogeneous porosity of Merck silica gel (grain size 0.2 to $0.5 \mathrm{~mm}$ ) and rather short equilibration times (1 day) used in experiments [35]. Logically, one can suppose that only a fraction of the total surface area was accessible (e.g. $\phi=0.2)$, and only a small fraction of the available surface sites had actually reacted. The GEM NEM run with $\phi=0.2$ already fits at $\mathrm{pH}<4$ though still greatly over-predicts at higher $\mathrm{pH}$ (dashed lines on Fig. 3c,d). To improve the fit, the $1>\mathrm{UO}_{2} \mathrm{OH}^{\circ}$ species was suppressed, and the $\Gamma_{\max , 2}$ parameter decreased; a reasonable fit was obtained at $\Gamma_{\max , 2}=0.00087 \mathrm{~nm}^{-2}$ (solid lines on Fig. 3c,d). Presumably, at longer equilibration times, diffusion into the internal porosity of the silica gel grains would proceed, and more sites would react with aqueous uranyl; in principle, such kinetics could be modelled by increasing $\Gamma_{\max , 2}$ with time. Experiments [35] seem to be done far from equilibrium, thus failing to conform with the general criteria of "critical review" of thermodynamic data, and, hence, will be excluded from further consideration. 


\subsection{The U(VI)-quartz sand system}

Pabalan et al. [30] measured sorption of U(VI) onto pretreated quartz sand in $0.1 \mathrm{M} \mathrm{NaNO}_{3}$ electrolyte at atmospheric $p_{\mathrm{CO}_{2}}-$ in a system similar to that by Kohler and Davis [2] (Sect. 6.1). Due to small $A=0.03 \pm 0.01 \mathrm{~m}^{2} \mathrm{~g}^{-1}$ of the sample, U(VI) surface coverages are higher. Experimental $K_{\mathrm{d}}$ data [30] were modelled using GEM implementation (Table 1) of the Davis and Kohler' NEM (accordingly changed to 20 or $50 \mathrm{~g} \mathrm{~L}^{-1} \mathrm{SiO}_{2}$ and $\mathrm{U}_{\text {тот }}=$ $2 \times 10^{-8} \mathrm{M} ; 2 \times 10^{-7} \mathrm{M}$; and $2.15 \times 10^{-6} \mathrm{M}$ ). However, satisfactory fits (not shown) could be obtained only at $50 \mathrm{~g} \mathrm{~L}^{-1}$ $\mathrm{SiO}_{2}$ and $\mathrm{U}_{\text {Tот }}=2.15 \times 10^{-6} \mathrm{M}$ at cost of a strong correction of $G_{298}^{\mathrm{o}}$ value for the $1>\mathrm{O}_{0.5} \mathrm{UO}_{2} \mathrm{CO}_{3}{ }^{-}$surface complex $(+6.85 \mathrm{~kJ}$ mol, or $1.2 \log K$ units weaker) and 4-times increase in the $\Gamma_{\max , 2}$ parameter (to $0.048 \mathrm{~nm}^{-2}$ ). All fits under-predicted adsorption of uranyl at $\mathrm{pH}<4.5$, especially at lower total $\mathrm{U}(\mathrm{VI})$ concentrations (10 times difference in $K_{\mathrm{d}}$ at $\mathrm{pH}=4.5$ and $\mathrm{U}_{\text {Tот }}=2 \times 10^{-8} \mathrm{M}$ ). This indicates that the surface of (even pre-treated) natural quartz sand grains exposes a different population of reactive surface sites (perhaps including sites on some hydroxide or silicate impurities), more heterogeneous than the surfaces of crushed quartz or non-porous synthetic silica used in other adsorption experiments. Hence, only qualitative interpretation of $K_{\mathrm{d}}$ data is possible in the framework of the existing $\mathrm{SCM}$, an the sand-U(VI) system is not a subject of further consideration.

\section{Development of GEM TLM for the U(VI)-silica system ("bottom-up" approach)}

Amphoteric surfaces of $\mathrm{SiO}_{2}$, am or quartz in aqueous solutions are negatively charged at $\mathrm{pH}>5$ due to the surface deprotonation. This charge may cause binding of electrolyte cations into the outer-sphere surface complexes, and may influence stability of the non-neutral inner-sphere surface complexes via the Coulombic term in Eq. (3). Therefore, application of a Stern-Graham type electrostatic SCM appears more rigorous than the NEM that simply ignores the Coulombic term. Among the available models (cf. [40]), the single-site $2 \mathrm{p} K$ "modified triple layer model" (TLM) [41] has been recently addressed theoretically [19] and applied to many mineral surfaces [10]; a similar TLM was im- plemented in GEM approach up to hydrothermal conditions $[14,15]$. Unlike CCM or DLM, the TLM includes outer-sphere complexes of electrolyte ions and thus accounts well for the ionic strength effects on surface charging behavior and weak adsorption. The modified TLM also accounts for the different mechanisms of metal adsorption because in TLM, the inner- and outer-sphere complexes can be combined on the same surface type. So, in our "bottom-up" approach, the U(VI) inner-sphere surface complexes will be incorporated into an existing GEM TLM for the silicon oxide-water interface [15]. TLM is known to describe surface charge development on silica phases in a wide range of ionic strength in various electrolytes [10].

\subsection{Stoichiometry of $\mathrm{U}^{\mathrm{VI}}$ surface complexes on silica mineral surfaces}

Recent XAFS studies of uranyl adsorption on silica elucidated a bidentate binding of equatorial oxygens of the $\mathrm{UO}_{2}{ }^{+2}$ ion to a single silica center. At $\mathrm{pH}=3.14$, no near-neighbor silicon or uranium is detected [32,33] pointing to existence of mononuclear U(VI) surface complexes, whereas at neutral $\mathrm{pH}(>6)$, shells of $\mathrm{Si}$ and $\mathrm{U}$ were detected at $3.1 \AA$ and $4.0 \AA$, respectively, indicating appearance of a uranyl polynuclear surface oligomer or precipitate [32]. In tune with XAFS results, Gabriel et al. [29,31] performed in situ observations of uranyl sorption speciation on silica using TRLIFS (time-resolved laser-induced fluorescence spectroscopy). After a sophisticated mathematical treatment, these authors inferred two mononuclear "fluorescent" (i.e. TRLIFS-detected) complexes, $\equiv \mathrm{SiO}_{2} \mathrm{UO}_{2}{ }^{\circ}$ and $\equiv \mathrm{SiO}_{2} \mathrm{UO}_{2} \mathrm{OH}^{-}$, which account for the bulk $\mathrm{U}(\mathrm{VI})$ adsorption at $\mathrm{pH}$ from 3 to 8 : the former with a peak at $\mathrm{pH} \approx 5$ and the latter at $\mathrm{pH}$ from 7 to 8.5. Third, $\equiv \mathrm{SiO}_{2} \mathrm{UO}_{2} \mathrm{OHCO}_{3}{ }^{-3}$ "non-fluorescence" (invisible by TRLIFS) ternary surface complex, was postulated to cover the difference (up to 35\%) between the sum of the concentrations of the fluorescent surface complexes and the experimentally determined total adsorbed uranyl concentration at $\mathrm{pH}>8$ [29]. Taken together, these arguments permit to write the following surface complexation reactions:

$$
\begin{array}{r}
2\left(>\mathrm{O}_{0.5} \mathrm{H}^{\mathrm{o}}\right)+\mathrm{UO}_{2}{ }^{+2}=\gg \mathrm{OUO}_{2}{ }^{\circ}+2 \mathrm{H}^{+} \\
\left(\gg \mathrm{OUL}^{\mathrm{o}}\right),
\end{array}
$$

Table 2. Initially fixed TLM parameters and thermodynamic data for the $\mathrm{U}(\mathrm{VI})-\mathrm{SiO}_{2}$ sorption aquatic system at

\begin{tabular}{|c|c|c|c|c|c|c|}
\hline Species & Reaction & $\begin{array}{l}\text { Elemental } \\
\text { stoichiometry }\end{array}$ & $\begin{array}{c}G_{298}^{\mathrm{o}} \\
\mathrm{kJ} \mathrm{mol}^{-1}\end{array}$ & $\log K^{a}$ & $\log K^{\mathrm{int} b}$ & Notes \\
\hline$>\mathrm{O}^{-} \mathrm{Na}^{+}$ & 25 & $\mathrm{O}_{0.5} \mathrm{Na}^{\mathrm{o}}$ & -348.19 & $-7.4^{c}$ & -7.0 & Outer-sphere \\
\hline$>\mathrm{OH}_{2}{ }^{+} \mathrm{NO}_{3}{ }^{-}$ & 26 & $\mathrm{O}_{0.5} \mathrm{H}_{2} \mathrm{NO}_{3}{ }^{\mathrm{o}}$ & -237.17 & $+0.4^{d}$ & +0.8 & Insignificant \\
\hline$>\mathrm{OH}_{2}^{+}$ & 15 & $\mathrm{O}_{0.5} \mathrm{H}_{2}^{+}$ & -122.27 & $+\mathbf{1 . 1}^{d}$ & +2.3 & Insignificant \\
\hline$>\mathrm{O}^{-}$ & 16 & $\mathrm{O}_{0.5}{ }^{-2}$ & -82.31 & $-8.1^{c}$ & -7.7 & \\
\hline$>\mathrm{OH}^{\circ}$ & 14 & $\mathrm{O}_{0.5} \mathrm{H}^{\mathrm{o}}$ & -128.55 & 1.74436 & - & Conventiona \\
\hline Quartz & & $\mathrm{SiO}_{2}$ & -854.79 & - & - & Sorbent \\
\hline $\mathrm{SiO}_{2}$, am & & $\mathrm{SiO}_{2}$ & -847.90 & - & - & $\begin{array}{l}\text { Alternative } \\
\text { sorbent }\end{array}$ \\
\hline
\end{tabular}
1 bar pressure and $25^{\circ} \mathrm{C}$ temperature.
Maximum competitive density set to $\Gamma_{\max }=4.6$ sites $\mathrm{nm}^{-2}$ [15] (i.e. $\Gamma_{\max }=2.3 \mathrm{~nm}^{-2}$ for bidentate surface complexes); TLM capacitance density parameters $C_{1}=1.0 \mathrm{~F} \mathrm{~m}^{-2} ; C_{2}=0.2 \mathrm{~F} \mathrm{~m}^{-2}$.

a: equilibrium constant (and standard $G_{298}^{\mathrm{o}}$ ) in molal concentration scale at $\Gamma_{\mathrm{o}}=12.05 \mathrm{~nm}^{-2}$;

b: at total/maximum site density parameter $\Gamma_{\mathrm{C}}=4.6$ sites nm ${ }^{-2}$, conversions using Eq. (7);

c: as in GEM TLM for $\mathrm{SiO}_{2}$, am in $\mathrm{NaCl}$ electrolyte [15];

$\mathrm{d}$ : assuming $\mathrm{pH}_{\mathrm{PPZC}}=3.5$ (and symmetric adsorption of $\mathrm{NaNO}_{3}$ electrolyte). 


$$
\begin{aligned}
& 2\left(>\mathrm{O}_{0.5} \mathrm{H}^{\mathrm{o}}\right)+\mathrm{UO}_{2}{ }^{+2}+\mathrm{H}_{2} \mathrm{O}=\gg \mathrm{OUO}_{2} \mathrm{OH}^{-}+3 \mathrm{H}^{+} \\
& \left(\gg \mathrm{OULH}^{-}\right) \text {, } \\
& 2\left(>\mathrm{O}_{0.5} \mathrm{H}^{\mathrm{o}}\right)+\mathrm{UO}_{2}{ }^{+2}+\mathrm{CO}_{2}{ }^{\circ}+2 \mathrm{H}_{2} \mathrm{O}= \\
& \gg \mathrm{OUO}_{2} \mathrm{OHCO}_{3}{ }^{-3}+5 \mathrm{H}^{+} \quad\left(\gg \mathrm{OULCH}^{-3}\right) \text {. }
\end{aligned}
$$

A "》" symbol denotes bidentate coordination to two primary silanol sites of $\Gamma_{\mathrm{o}}$ density, whereas "> " indicates the monodentate coordination; for brevity, the surface species will be referred to using their names in parentheses. As required in the single-site $2 \mathrm{p} K$ TLM formulation, reactions (14) to (16) describe "pristine" surface hydration and deprotonation; two more reactions depict the outer-sphere surface complexation of electrolyte ions:

$$
\begin{aligned}
& >\mathrm{O}_{0.5} \mathrm{H}^{\mathrm{o}}+\mathrm{Na}^{+}=>\mathrm{O}_{0.5}{ }^{-} \mathrm{Na}^{+}+\mathrm{H}^{+} \quad\left(>\mathrm{O}^{-} \mathrm{Na}^{+}\right)^{(25)} \\
& >\mathrm{O}_{0.5} \mathrm{H}_{2}{ }^{+} \mathrm{NO}_{3}{ }^{-}=>\mathrm{O}_{0.5}{ }^{\mathrm{o}}+\mathrm{H}^{+}+\mathrm{NO}_{3}{ }^{-} \quad\left(>\mathrm{OH}_{2}{ }^{+} \mathrm{NO}_{3}{ }^{-}\right) .
\end{aligned}
$$

Thermodynamic data for reactions (14) to (16), (25) and (26) are listed in Table 2. Note that $\mathrm{pH}_{\mathrm{PZC}}$ (point of zero charge) for quartz and $\mathrm{SiO}_{2}$, am phases is low $\left(\mathrm{pH}_{\mathrm{PZC}}=3.5\right.$ is assumed here), hence the protonated $>\mathrm{OH}_{2}{ }^{+} \mathrm{NO}_{3}{ }^{-}$and $>\mathrm{OH}_{2}{ }^{+}$surface species (included for completeness of the TLM) are weak and do not make a significant contribution at $\mathrm{pH}>3$.

\subsection{TLM fitting for the U(VI)-amorphous silica system}

The same GEM setup of the chemical system was taken as described in Sect. 6.2, only the NEM surface species were replaced by TLM species, and the required Coulombic corrections were activated. All surface complexes were first assigned a competitive SAT (Eq. (11)) at $\Gamma_{\max }=$ $4.6 \mathrm{~nm}^{-2}$ [10]. Direct GEM fitting of $G_{298}^{\mathrm{o}}$ values of three bidentate uranyl surface complexes (reactions 22 to 24) began using data $[29,31]$ because of a possibility to compare the calculated and the in situ observed surface speciation. The "best" fit (Fig. 4a) was obtained at the $G_{298}^{\text {o }}$ values listed in Table 3, from which the equilibrium constants at reference density $\Gamma_{\mathrm{o}}=12.05 \mathrm{~nm}^{-2}$ were calculated.

Comparison of the modelled surface speciation with that suggested by Gabriel et al. [Fig. 6 in 29] shows that the neutral $\gg$ OUL $^{\circ}$ species curve has a peak at $\mathrm{pH}$ between 4.4 to 4.8 , in full accordance with TRLIFS observations. However, the second, $\gg \mathrm{OULH}^{-}$complex with one negative charge has a maximum at $\mathrm{pH}$ between 5.5 and 6.5 , while TRILFS data suggest it to be located at $\mathrm{pH}$ between 7.0 and 8.5. The crossover of density curves for both surface species is located at $\mathrm{pH} \approx 4.9$ (Fig. 4a) instead of the observed $\mathrm{pH}$ from 5.5 to 6.0. The $\gg \mathrm{OULH}^{-}$curve drops with the increasing $\mathrm{pH}$ rather steeply already from $\mathrm{pH}=6.5$, and this has to be compensated by a relatively high density of the $\gg \mathrm{OULCH}^{-3}$ ternary surface complex, thought to be weak on silica surfaces [29].

Since spectroscopy data cannot provide exact information about formula charges of uranyl surface hydroxocomplexes, an obvious improvement of the TLM is to try stoichiometries with higher negative charges, to boost their densities at $\mathrm{pH}>6$ by stronger Coulombic terms in response
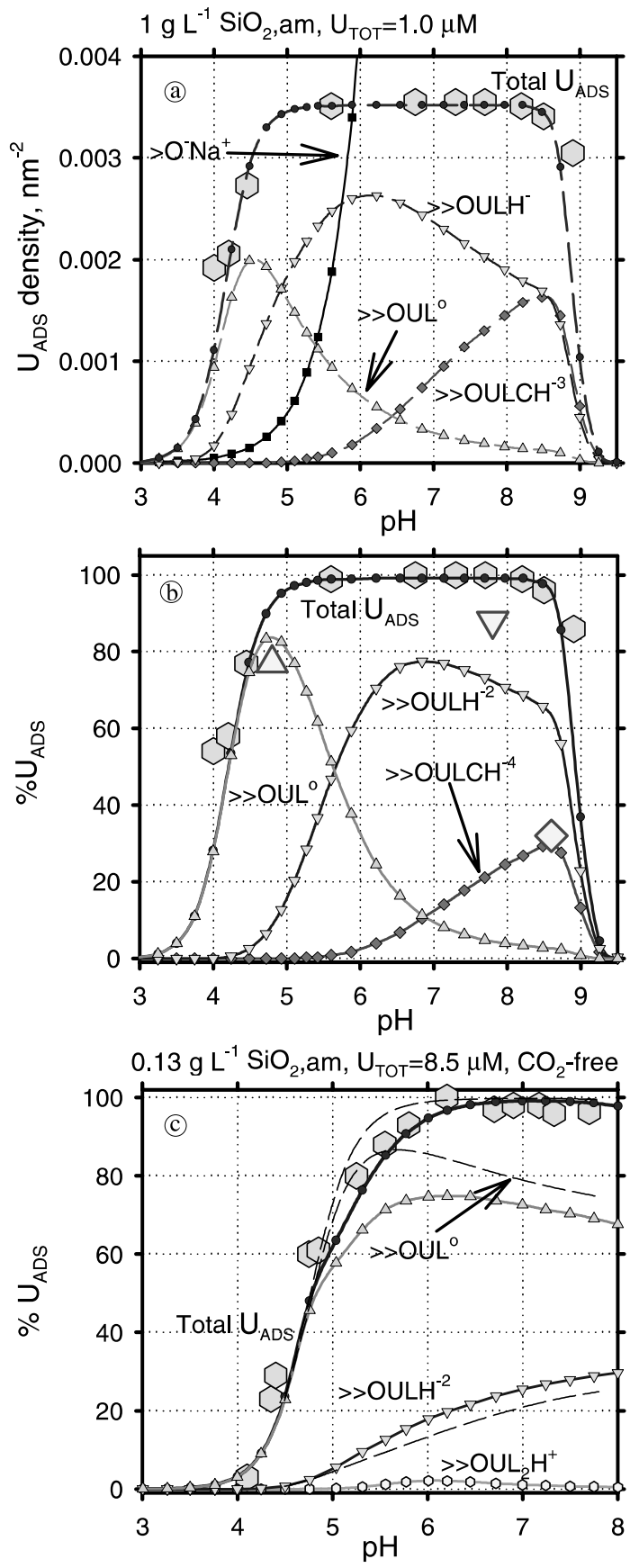

Fig. 4. Adsorption of U(VI) on amorphous silica at ambient conditions, GEM TLM fits. (a): surface speciation (expressed in density of uranium atoms per $\mathrm{nm}^{-2}$ ) calculated using data from Tables 2 and 3, large hexagons are experimental data [29], solid curve with squares shows density of the TLM outer-sphere $>\mathrm{O}^{-} \mathrm{Na}^{+}$species in sites $\mathrm{nm}^{-2}$; (b): the same experimental data modeled with GEM TLM (Tables 2 and 4), large triangles and a diamond show approximate maxima of in situ detected [29] uranyl surface complexes; (c): $\mathrm{CO}_{2}$-free system [34], thin dashed lines using data of Table 4 without SAT corrections, solid lines - applying SAT with $\Gamma_{\max }=0.18 \mathrm{~nm}^{-2}$ to the $\gg \mathrm{OUL}^{\circ}$ species.

to a buildup of negative surface charge. Therefore, two new stoichiometries were introduced via the reactions:

$$
\begin{aligned}
& 2\left(>\mathrm{O}_{0.5} \mathrm{H}^{\mathrm{o}}\right)+\mathrm{UO}_{2}{ }^{+2}+2 \mathrm{H}_{2} \mathrm{O}=\gg \mathrm{OUO}_{2}(\mathrm{OH})_{2}{ }^{-2}+4 \mathrm{H}^{+} \\
& \left(\gg \mathrm{OULH}^{-2}\right) \text {, } \\
& 2\left(>\mathrm{O}_{0.5} \mathrm{H}^{\mathrm{o}}\right)+\mathrm{UO}_{2}{ }^{+2}+\mathrm{CO}_{2}{ }^{\circ}+3 \mathrm{H}_{2} \mathrm{O}= \\
& \gg \mathrm{OUO}_{2}(\mathrm{OH})_{2} \mathrm{CO}_{3}{ }^{-4}+6 \mathrm{H}^{+} \quad\left(\gg \mathrm{OULCH}^{-4}\right),
\end{aligned}
$$


Table 3. $G_{298}^{\mathrm{o}}$ and $\log K$ values for the initial stoichiometries of uranyl surface complexes (see Fig. 4a)

\begin{tabular}{llcccc}
\hline $\begin{array}{l}\text { Surface species } \\
\text { name on plots }\end{array}$ & $\begin{array}{l}\text { Elemental } \\
\text { formula }\end{array}$ & $\begin{array}{c}G_{298}^{\mathrm{o}} \\
\mathrm{kJ} \mathrm{mol}^{-1}\end{array}$ & Reaction & $\log K$ & $\begin{array}{c}\log K^{\text {int }} \\
\mathrm{CCM}[29]^{b}\end{array}$ \\
\hline$\gg \mathrm{OUL}^{\mathrm{o}}$ & $\mathrm{UO}_{3}{ }^{\circ}$ & -1166.90 & 22 & $-7.5^{a}$ & -6.33 \\
$\mathrm{OULH}^{-}$ & $\mathrm{UO}_{3} \mathrm{OH}^{-}$ & -1377.14 & 23 & $-12.22^{a}$ & -11.95 \\
$\gg \mathrm{OULCH}^{-3}$ & $\mathrm{UO}_{3} \mathrm{OHCO}_{3}{ }^{-3}$ & -1961.64 & 24 & $-19.0^{a}$ & -23.64 \\
\hline
\end{tabular}

a: $\log K$ values calculated from $G_{298}^{o}$ values and reaction stoichiometries using the ReacDC module of GEM-Selektor code (see Appendix for the auxiliary thermodynamic data);

b: For comparison; converted from $\Gamma_{\mathrm{C}}=1.82$ sites nm ${ }^{-2}$ [29] to $\Gamma_{\mathrm{o}}$ by applying Eq. (7) twice. CCM stands for the "constant capacitance model".
Table 4. Fitted thermodynamic data and other parameters of GEM TLM for the U(VI)quartz (silica) aquatic sorption system.

\begin{tabular}{|c|c|c|c|c|c|c|c|}
\hline $\begin{array}{l}\text { Surface species } \\
\text { name on figures }\end{array}$ & $\begin{array}{l}\text { Elemental } \\
\text { stoichiometry }\end{array}$ & $\begin{array}{c}G_{298}^{\mathrm{o}} \\
\mathrm{kJ} \mathrm{mol}^{-1}\end{array}$ & $\begin{array}{c}\Gamma_{\max } \\
\mathrm{nm}^{-2}\end{array}$ & Reaction & $\log K^{a}$ & $\log K^{\text {int } b}$ & $\log K^{\text {int } c}$ \\
\hline$\gg \mathrm{OUL}^{\circ}$ & $\mathrm{UO}_{3}{ }^{\circ}$ & -1166.90 & 0.14 & 22 & $-7.5 \pm 0.3$ & -7.1 & -6.7 \\
\hline$\gg \mathrm{OULH}^{-2}$ & $\mathrm{UO}_{3}(\mathrm{OH})_{2}{ }^{-2}$ & -1582.47 & 0.14 & 27 & $-17.8 \pm 0.3$ & -17.4 & -17.0 \\
\hline$\gg \mathrm{OULCH}^{-4}$ & $\mathrm{UO}_{3}(\mathrm{OH})_{2} \mathrm{CO}_{3}^{-4}$ & -2165.14 & $>1.0$ & 28 & $-24.9 \pm 1.0$ & -24.5 & -24.1 \\
\hline$\gg \mathrm{OUL}_{2} \mathrm{H}^{+}$ & $\mathrm{O}\left(\mathrm{UO}_{2}\right)_{2} \mathrm{OH}^{+}$ & -2341.85 & $>1.0$ & 29 & $-10.1 \pm 0.3$ & -9.7 & -9.3 \\
\hline
\end{tabular}

a: equilibrium constant (and standard molal $G_{298}^{\mathrm{o}}$ ) at reference density $\Gamma_{\mathrm{o}}=12.05 \mathrm{~nm}^{-2}$;

b: at the total/maximum density parameter $\Gamma_{\mathrm{C}}=4.6$ species $\mathrm{nm}^{-2}$, conversions using Eq. (7);

c: at LMA balance site density parameter $\Gamma_{\mathrm{C}}=4.6$ sites $\mathrm{nm}^{-2}$, after second conversion using Eq. (7). inserted into GEM system formulation instead of the species defined in Eqs. $(23,24)$, and the $G_{298}^{\mathrm{o}}$ were fitted in GEM batch runs (Table 4). The obtained TLM speciation (Fig. $4 \mathrm{~b}$ ) now shows a much higher peak of the $\gg \mathrm{OUL}^{\circ}$ species at correct $\mathrm{pH}=4.6$. The $\gg \mathrm{OULH}^{-2}$ curve also compares favourably with that of the "second fluorescent surface complex", at only a modest contribution of the hypothetical ternary uranyl-hydroxo-carbonato species. Note that in this system, U(VI) surface coverage is small $\left(<0.0036 \mathrm{~nm}^{-2}\right)$ and SAT corrections do not work. Hence, adsorption of uranyl is completely determined by thermodynamic data, plus capacitance parameters $\mathrm{C} 1$ and $\mathrm{C} 2$ affecting the TLM Coulombic corrections (Tables 2 and 4).

Is the new TLM for $\mathrm{U}(\mathrm{VI})$ adsorption applicable to other silica sorbents at different experimental conditions? This has been checked by applying the above model "as is" in GEM runs for the titration data of Turner et al. [34] in the $\mathrm{CO}_{2}$-free system. Results of this exercise (dashed thin lines on Fig. 4c, compare with Fig. 3a) show a satisfactory fit, somewhat over-predicting uranyl adsorption at $\mathrm{pH}$ from 5.0 to 6.5 at cost of the $\gg \mathrm{OUL}^{\circ}$ species. As the surface coverage of $\mathrm{U}(\mathrm{VI})$ in this system $\left(0.13 \mathrm{~g} \mathrm{~L}^{-1}\right.$ silica, $\mathrm{U}_{\text {тот }}=8.5 \times 10^{-6} \mathrm{M}$ ) is much greater than previously, the site heterogeneity may play a role, and a new fitting parameter $\left(\Gamma_{\max }\right.$ for SAT correction of the $\gg \mathrm{OUO}_{2}{ }^{\circ}$ density) can be introduced. Indeed, the fit is improved (solid lines with small symbols on Fig. 4c) by setting $\Gamma_{\max }\left(\gg \mathrm{OUL}^{\circ}\right)=0.18 \mathrm{~nm}^{-2}$. This sample-specific $\Gamma_{\max }$ parameter is involved only into an individual SAT correction factor (Eq. (9)) and leaves the sandard $G_{298}^{\circ}$ values (Table 4) unchanged. Precaution: such fits (in LMA or GEM implementation) against a single $\mathrm{pH}$ step data can be considered neither as a mechanistic evidence about the molecular environment of uranyl on silica surfaces, nor as a proof that the binding sites of limited availability actually exist on mineral-water interface (which is by far more complex than any SCM can represent).

\subsection{Application of GEM TLM to the U(VI)-crushed quartz system}

A more serious test of the new TLM thermodynamic dataset for $\mathrm{U}(\mathrm{VI})$ adsorption on $\mathrm{SiO}_{2}$ phases consists in modeling experimental $\mathrm{pH}$ step data for $\mathrm{U}(\mathrm{VI})$ adsorption on crushed quartz [2], which were taken as a starting point of the NEM "top-down" exercise (Sect. 6). Again, the GEM system formulation was upgraded by replacing the NEM quartz sorption phase definition by the TLM quartz sorption phase (see Tables 2 and 4), then the GEM-Selektor batch runs for different total U(VI) concentrations were performed again. As seen on Fig. 5a, at $\mathrm{U}_{\text {Tот }}=1 \times 10^{-6} \mathrm{M}$, the "as is" TLM yields quite a good fit, confirming its validity for various $\mathrm{SiO}_{2}$ sorbents and samples (and, probably, various concentrations of background electrolytes because there is no significant ionic strength effect at $\mathrm{pH}<7$ [2]). The calculated surface speciation pattern is similar to that on Fig. $4 \mathrm{~b},-$ and even more resembles the TRLIFS - observed speciation.

However, the GEM TLM runs at $\mathrm{U}_{\text {Tот }}=1 \times 10^{-8} \mathrm{M}$ reveal some new details (dashed lines with symbols on Fig. 5b). The model now under-predicts uranyl adsorption in 10 to $30 \%$ at $\mathrm{pH}<5$. A possible explanation would be a heterogeneity of crushed quartz surfaces, where a small population of high-affinity sites (vacansies, dislocations, inclusions or impurities) may exist, and it may affect the $\mathrm{U}(\mathrm{VI})$ adsorption at very low surface coverage. To test this assumption, a second "strong" $\gg \mathrm{OUL}^{\circ}$ species was temporarily included, with $G_{298}^{\mathrm{o}}=-1172.6 \mathrm{~kJ} \mathrm{~mol}^{-1}$, i.e. $4.57 \mathrm{~kJ} \mathrm{~mol}^{-1}$ more negative, or $0.8 \log K$ units stronger than the regular $\gg \mathrm{OUL}^{\circ}$ species. GEM batch calculations were repeated while adjusting the $\Gamma_{\max }$ value for individual SAT correction of the "strong" $\gg \mathrm{OUL}^{\circ}$ surface complex (pointed by an arrow on Fig. 5b). A nice fit (thin solid lines) is obtained at a very small $\Gamma_{\max }\left(\gg \mathrm{OUL}^{\circ}\right.$, strong $)=$ $8 \times 10^{-5} \mathrm{~nm}^{-2}$. Note that, due to chemical mass action, presence of the "strong" species decreases densities of the "regular" $\gg \mathrm{OUL}^{\circ}$ and $\gg \mathrm{OULH}^{-2}$ complexes at about $20 \%$, Brought to you by | Lib4RI Eawag-Empa Authenticated 

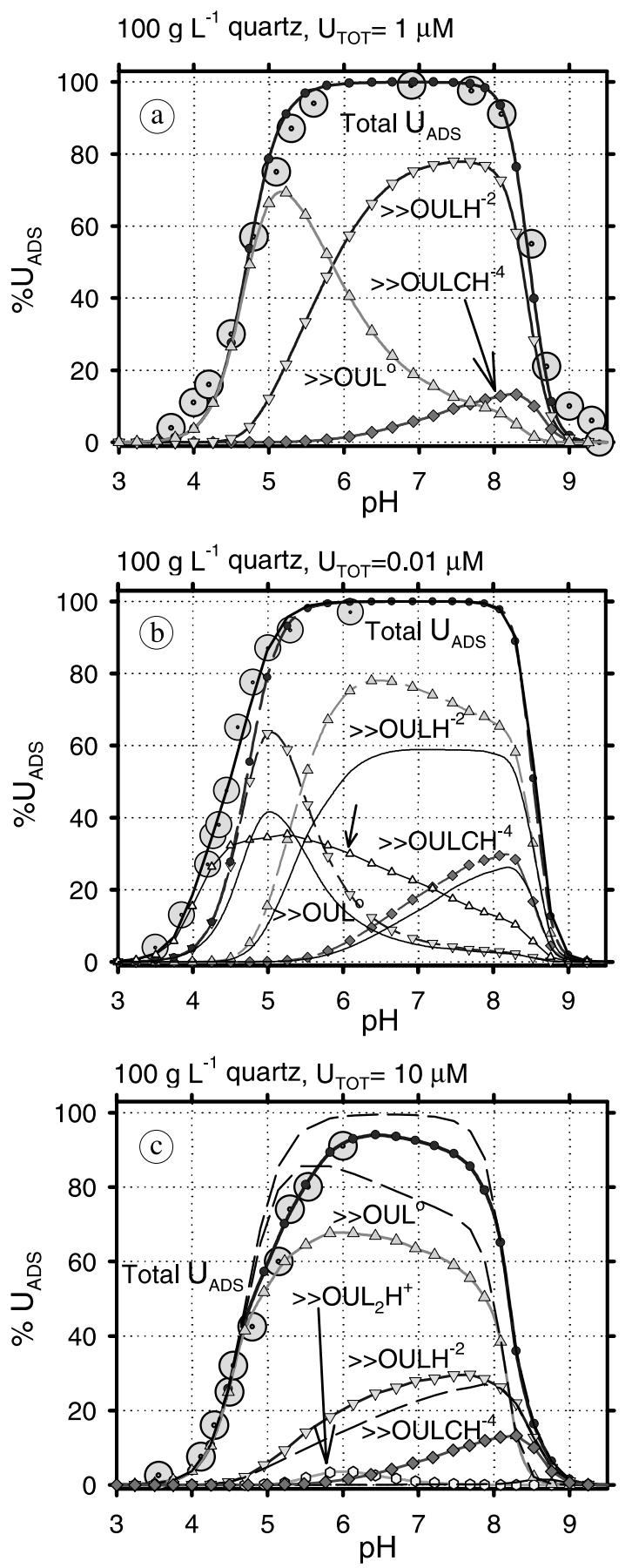

Fig. 5. Adsorption of U(VI) on crushed quartz, GEM TLM fits, experimental data [2] (large circles). (a): uranyl adsorption and surface speciation $\left(\% \mathrm{U}_{\text {ads }}\right)$ at $10^{-6} \mathrm{M}$ total uranium, calculated using data from Table 4; (b): the same at $10^{-8} \mathrm{M}$ total uranium (dashed lines with symbols), plus a hypothetical "strong" $\gg \mathrm{OUL}^{\circ}$ surface complex with $\Gamma_{\max }=8 \times 10^{-5} \mathrm{~nm}^{-2}$ (thin solid lines); (c) uranyl adsorption and surface speciation at $10^{-5} \mathrm{M}$ total uranium (TLM parameters from Tables 2 and 4) with $\Gamma_{\max }=0.14 \mathrm{~nm}^{-2}$ for SAT of the $\gg \mathrm{OUL}^{\circ}$ species (solid lines) and with disabled SAT correction (dashed lines).

but density of the (hypothetical) ternary uranyl-hydroxocarbonato surface complex is much less affected. At $\mathrm{U}_{\text {тот }} \geq$ $1 \times 10^{-7} \mathrm{M}$, increment of the "strong" $\gg \mathrm{OUL}^{\circ}$ species is negligible due to its low maximum density, and there is generally no need to include it into the TLM.

In the region of high surface coverage $\left(\mathrm{U}_{\text {Tот }}=\right.$ $\left.1 \times 10^{-5} \mathrm{M}\right)$, the "regular" TLM shows an inverse trend (dashed lines on Fig. $5 \mathrm{c}$ ) - now it fits quite well at $\mathrm{pH}<4.8$
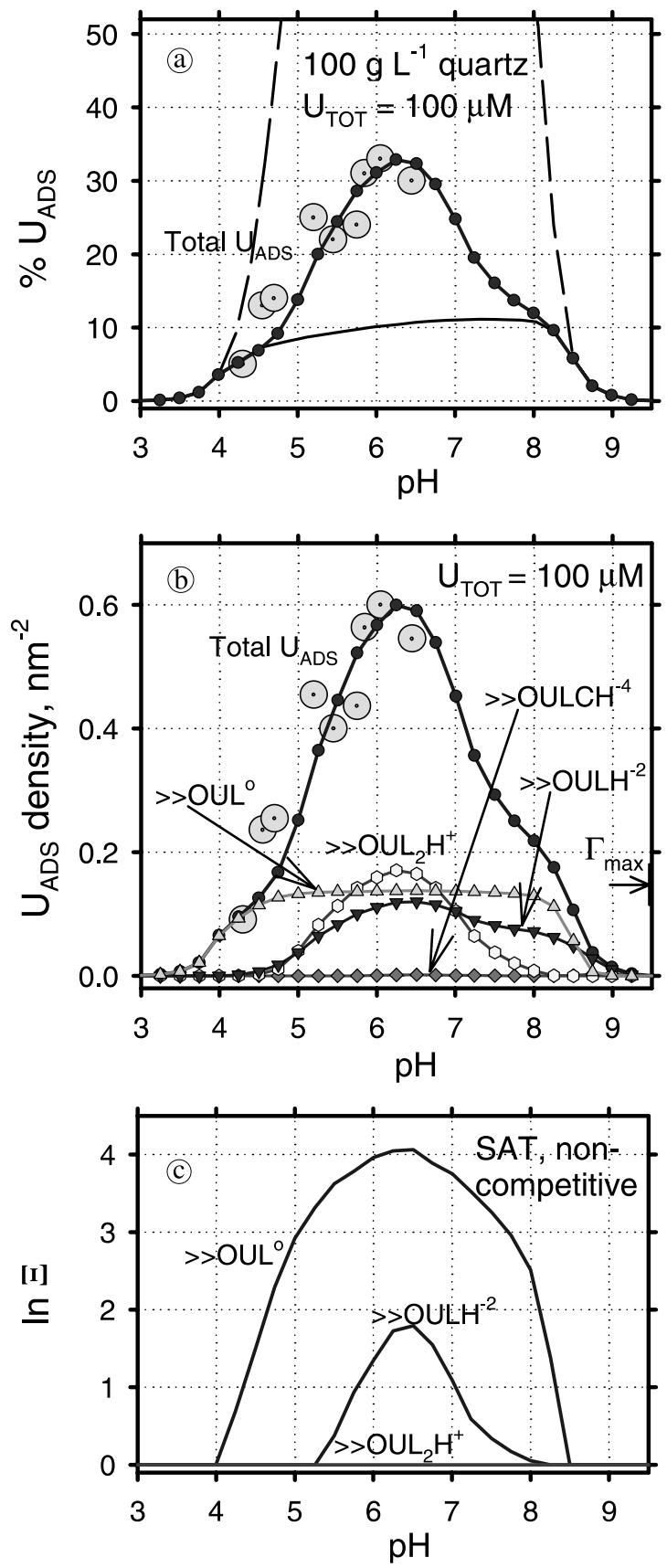

Fig. 6. Adsorption of U(VI) on crushed quartz, GEM TLM fits (continued). (a): uranyl adsorption at $10^{-4} \mathrm{M}$ total $\mathrm{U}$, calculated with data of Tables 2 and 4 without individual SAT corrections for $\gg \mathrm{OUL}^{\circ}$ and $\gg \mathrm{OULH}^{-2}$ species (dashed line); with $\Gamma_{\max }=0.14 \mathrm{~nm}^{-2}$ set for both species (thin solid line); and the binuclear $\gg \mathrm{OUL}_{2} \mathrm{H}^{+}$surface complex plus non-competitive SAT corrections at $\Gamma_{\max }=0.14 \mathrm{~nm}^{-2}$ for $\gg \mathrm{OUL}^{\circ}$ and $\gg \mathrm{OULH}^{-2}$ species (solid line with circles). (b) total $\mathrm{U}_{\text {ads }}$ and surface speciation at $\mathrm{U}_{\text {тот }}=10^{-4} \mathrm{M}$ calculated using the complete GEM TLM parameter set for uranyl surface complexes (Table 4); (c): behaviour of SAT correction values corresponding to the surface speciation shown in $(\mathbf{b})$.

but over-predicts up to $15 \%$ the uranyl adsorption at $\mathrm{pH}>5$. As in the case of $\mathrm{SiO}_{2}$, am (Fig. 4c), the site availability seems to be limited for the $\gg \mathrm{OUL}^{\circ}$ species. To improve the model, an additional fitting parameter (individual $\Gamma_{\max }$ for $\gg \mathrm{OUL}^{\circ}$ species) was introduced, yielding a good fit also at $\mathrm{pH}>5$ (solid lines with small symbols on Fig. 5c) at $\Gamma_{\max }=0.14 \mathrm{~nm}^{-2}$. This value is surprisingly similar to $0.18 \mathrm{~nm}^{-2}$ obtained in Sect. 7.2. Fortuitous, - or indeed, the Brought to you by | Lib4RI Eawag-Empa 
structure of silica minerals poses certain crystallographic limits to the density of monomeric uranyl surface complexes? At least for modelling purposes, we will assume that $\Gamma_{\max }=0.14$ to $0.18 \mathrm{~nm}^{-2}$ is a non-thermodynamic property of the $\gg \mathrm{OUO}_{2}{ }^{\circ}$ surface complex on silica, somewhat in parallel with e.g. Kielland's semi-empirical "ion-size" parameters (cf. [39]) used in the Debye-Hueckel activity coefficient equation for aqueous ionic species.

The GEM batch runs at $\mathrm{U}_{\text {Tот }}=1 \times 10^{-4} \mathrm{M}$ (Fig. 6) further point to importance of the surface heterogeneity effects at high uranium loadings. Runs without $\mathrm{SAT}=f\left(\Gamma_{\max }\right)$ corrections for the $\gg \mathrm{OUL}^{\circ}$ and $\gg \mathrm{OULH}^{-2}$ species strongly over-predict U(VI) adsorption on quartz (dashed lines on Fig. 6a). Adding individual SAT corrections with $\Gamma_{\max }=$ $0.14 \mathrm{~nm}^{-2}$ for both complexes now results in up to $20 \%$ under-prediction at $\mathrm{pH}$ from 5 to 8 (thin solid line on Fig. 6a). Setting $\Gamma_{\max }$ for either of the two dominant species still results in a strong over-prediction by another species (not shown). A reasonable assumption is that at high dissolved U(VI) (but below solubility of uranyl hydroxide or silicate minerals), oligomeric U(VI) surface species must form on the silica or quartz surface, - as it has been found in the EXAFS studies indeed $[32,33]$.

This idea leads to extension of the silica/quartz TLM list of $\mathrm{U}(\mathrm{VI})$ surface complexes with a simple binuclear uranyl hydroxocomplex $\gg \mathrm{OUL}_{2} \mathrm{H}^{+}$(simplification of the molecular reality, in which various tri-, tetra-, ... nuclear stoichiometries should be possible, up to formation of the uranyl-hydroxide surface clusters):

$$
\begin{aligned}
2\left(>\mathrm{O}_{0.5} \mathrm{H}^{\circ}\right)+2 \mathrm{UO}_{2}^{+2}+\mathrm{H}_{2} \mathrm{O}= & \gg \mathrm{O}_{\left(\mathrm{UO}_{2}\right)_{2} \mathrm{OH}^{+}+3 \mathrm{H}^{+}} \\
& \left(\gg \mathrm{OUL}_{2} \mathrm{H}^{+}\right) .
\end{aligned}
$$

Adjustment of its $G_{298}^{\mathrm{o}}$ value (see Table 4) results in a good TLM fit to the measured adsorbed uranyl fraction at $\mathrm{U}_{\text {TOT }}=$ $1 \times 10^{-4} \mathrm{M}$ (solid line with small circles on Fig. 6a,b). Accumulation of the binuclear adsorbed species of U(VI) occurs along with the non-linear behaviour of $\gg \mathrm{OUL}^{\circ}$ and $\gg \mathrm{OULH}^{-2}$ species, which both develop quite large SAT values (Fig. 6c). This points to a much lesser stability of the binuclear uranyl surface complex as compared to the mononuclear species; quite reasonably, the surface oligomers are expected to form at high dissolved uranium concentrations, only when there is a deficiency in surface sites available to form monomeric U(VI) complexes. Indeed, already at $\mathrm{U}_{\text {Tот }} \approx 10^{-5} \mathrm{M}$, less than $3 \%$ of adsorbed uranium may be bound into the $\gg \mathrm{OUL}_{2} \mathrm{H}^{+}$species (Figs. $4 \mathrm{c}$ and $5 \mathrm{c}$ ), which become totally negligible at $\mathrm{U}_{\mathrm{TOT}} \leq 10^{-6} \mathrm{M}$.

\section{Concluding remarks}

SCMs are site-binding speciation models that describe macroscopic adsorption behaviour of aqueous solutes at mineral-water interfaces using chemical mass action law [1, 40]. As shown in Sects. 2 and 3 above, at equilibrium, binding of aqueous ions into surface monolayer can also be described using the formalism of chemical thermodynamics, provided that: (1) mole quantity and effective specific surface area of the sorbent are given; (2) elemental stoichiometries of surface-bound species are known; (3) their standard and reference states are unequivocally defined by convention. It can be shown also that close to the reference state (at zero surface charge/potential, large sorbent surface and small concentration of aqueous sorbate), in the "linear adsorption region", concentration of a surface species is governed only by its chemical potential, and $\Gamma_{\max }$ constraint is obsolete [15]. Thus, standard thermodynamic properties such as $G^{\circ}$ (or $K$ ) can be determined from the macroscopic adsorption data at low surface coverage even using the NEM SCM.

Far from the reference state, three complications occur that require non-thermodynamic corrections of surface species concentration relative to that dictated by the chemical potential. (A) Density of reactive sites available for the monolayer binding of a sorbate may be limited by crystallographic or other physical constraints, and this limit may be approached (as expressed in the Langmuir isotherm), sometimes with help of other competing surface species. This effect can be simulated by adding a mass balance constraint for the total moles of binding sites per surface type (always done in LMA and possible in GEM codes). Alternatively, the density of surface species can be suppressed using a SAT correction (Eq. (9)) - a function of $\Gamma_{\max }$ involving the Langmuir term (Eq. (8)), - which obviates the need of additional balance constraints (done in GEM and possible in LMA codes). (B) Adjacent surface-bound species on real (rough) surfaces may interact laterally in poorly-understood physical phenomena, in principle, accountable for through activity coefficients (those cannot be measured and are usually assumed to cancel out in the LMA expressions). (C) Amphoteric oxide surfaces in water develop negative or positive surface charge in response to addition of base or acid to the bulk aqueous electrolyte. This is traditionally described via the Coulombic correction term (Eq. (3)) that depends on the charge-potential relationship for a particular mineral-water interface, and requires application of an electrostatic SCM.

Electrostatic SCMs differ in their underlying physicochemical description of the interface structure, hence, in the required sets of surface species, EDL planes, charge density balance, and parameters to define the Coulombic term as function of surface charge and ionic strength (see a comparison [40]). However, from the viewpoint of chemical thermodynamic formalism, SCMs just provide specific functions for correction of densities of non-neutral surface complexes away from their reference states. If so, then standard thermodynamic values $\left(G^{\circ}, \log K\right)$ and activities of adsorbed species must depend on their stoichiometry but not on a particular Coulombic correction at non-zero surface charge.

Recently developed surface spectroscopy techniques open a way to determine stoichiometries of adsorbed species and link them to crystallographic structure of the sorbent surface, thus constraining the SCM formulation. Subsequently, the available macroscopic titration data sets (for various metal concentrations, solid/water ratios, specific surface areas, $\mathrm{pH}$ and ionic strength) can be critically selected, and standard-state properties of surface species can be found by fitting with GEM or LMA speciation codes, preferably starting at low surface coverages $[15,42]$. If thus obtained values of $K^{\text {int }}$ (or $G^{\circ}$ ) describe well the bulk of selected sets of macroscopic titration data without the SAT $=f\left(\Gamma_{\max }\right)$ correction, except that at extremely high or low surface coverages (where different binding mechanisms 
and adsorbed species can be involved), then this is a serious indication towards a possible extension of the uniform thermodynamic adsorption database, with a good chance that this extension will eventually be accepted by scientific community. One should keep in mind, however, that any thermodynamic model (SCMs in particular) is a strong simplification of a quite complex reality under assumption of (at least local/partial) equilibrium, providing just a "reference point" or a "final state", nevertheless (often surprisingly) helpful in understanding complex, time-dependent geochemical processes deemed to occur, for instance, in the near field of a nuclear waste repository.

This philosophical sidebar helps in comparing two modelling examples that illustrate alternative approaches in acquisition of standard thermodynamic data of surface complexes. The "top-down" approach results at least in a broader applicability of $\log K$ (or $G^{\circ}$ values) of U(VI) surface complexes to chemically similar sorbents, as shown for quartz and amorphous silica (Sect. 6). To what extent such constants can be taken as standard thermodynamic data? Obviously, this greatly depends on the underlying physicochemical assumptions, fully inherited from the original SCM, and on the choice of surface site types and surface species stoichiometry. If this choice is based solely on the "goodnessof-fit" criteria, without any supporting crystallographic and spectroscopic observations, and if no reasonable electrostatic correction is applied to concentrations of the adsorbed species on oxide surface with a significant variable charge then SCM is nothing but a fitting exercise, and the obtained $G^{\circ}$ or $\log K$ values cannot be accepted as chemical thermodynamic data per se. However, this does not mean that such standard-state constants (or the original $K^{\text {int }}$ values) are useless: they do have a predictive power at least within a variety of sorbents and systems used in parameterization; SCM is still a generator of "smart" $K_{\mathrm{d}}$ values for surface $\mathrm{U}(\mathrm{VI})$ sorption.

For many literature titration data sets where crystallographic and micro/spectroscopic data are not available, the "top-down" approach seems to be the only feasible way, at least, to standardize the SCM "smart $K_{\mathrm{d}}$ generation" (using either LMA or GEM codes), if at least specific surface area of the sorbent is known, and only surface uptake of dissolved sorbates is assumed (otherwise, the solid solution-aqueous solution thermodynamic models appear to be more appropriate). However, for a growing variety of mineral-water interfaces, results of recent microscopic, spectroscopic, crystallographic, and molecular dynamic simulation studies help greatly in defining stoichiometries of surface complexes existing at certain $\mathrm{pH}$ and surface loading conditions. For instance, this seems to be a case with the U(VI)- $\mathrm{SiO}_{2}$, am sorption system (see Sect. 7) or the U(VI)-Fe(III) (hydr)oxide system $[2,26]$. Such data can serve as an origin for an alternative, more advanced routine of thermodynamic data acquisition.

In the "bottom-up" approach (Sect. 7), the direct fitting of $G^{\circ}$ values using GEM algorithm appears to be preferable over the fitting of $K^{\text {int }}$ values with LMA codes (e.g. [4]) for the following reasons. As discussed in Sect. 4, atoms of the sorbent should not be included into formulae of surface species to avoid making their standard-state properties dependent on composition of the sorbent surface layer, which in many cases (e.g. clay particles, humate colloids etc.) is difficult or impossible to define. In the context of classic $2 \mathrm{p} K$ SCMs, the required separation can be done by assigning the oxygen atom of every second primary $\equiv \mathrm{OH}$ group to the surface species and leaving another oxygen to the sorbent. Thus, formula of the primary $\equiv \mathrm{OH}$ group of reference density $\Gamma_{\mathrm{o}}$ ("surface solvent") will be $\mathrm{O}_{0.5} \mathrm{H}^{\mathrm{o}}$; then, formulae of all surface complexes can be derived from the respective ligand exchange (for adsorbed anions) or surface complexation (for cations) reactions, luckily supported by the spectroscopic insights. If stoichiometry of a surface complex contains only chemical elements and charge, and this complex is present in non-zero quantity at the equilibrium state, then chemical potential of any element (e.g. uranium) in this surface complex must be the same as in any other (e.g. aqueous or solid) species present in other coexisting phases in the system.

In GEM-Selektor numerical iterations, the value of relative chemical potential $u_{i}$ of every $i$-th element and electrical charge is adjusted in direction of bringing the total Gibbs energy of the whole chemical system closer to the global minimum [11]. Upon convergence, the chemical potential of any $j$-th (surface) species in any phase can be calculated in two ways: (1) from its mole quantity $x_{j}$ (Eq. (3) for surface species) involving various scaling, SAT and Coulombic corrections; (2) directly from the "dual solution" $u_{i}$ values and the chemical formula of the species [12]:

$$
\mu_{j}=\sum_{i} a_{i j} u_{i},
$$

where $a_{i j}$ is a chemical formula stoichiometry coefficient (e.g. 1 for $\mathrm{U}$ and 3 for $\mathrm{O}$ in $\mathrm{UO}_{3}$ ). If standard partial molal Gibbs energy of a surface species is known then its activity is uniquely fixed according to Eq. (12), and, from Eq. (13), a unique value of its mole quantity $x_{j}$ (hence, surface density or molal concentration) can be found in the framework of the chosen set of the SCM and SAT corrections. Thus, in case of direct fitting of $G^{\circ}$ values for elemental stoichiometries of the surface species, the GEM parameterisation is unique in determining the activity $\left(a_{j}=\mu_{j}-\mu_{j}^{\circ}\right)$ of each surface complex. Only the mole quantity $x_{j}$ (and surface concentration) depends on the choice of the (non) electrostatic SCM and (rarely) on the $\Gamma_{\max }$ value. Whether the $\equiv \mathrm{OH}$ group is actually included into GEM SCM or not, plays no role in model titration curves, whose shapes are defined solely by chemical potentials (and, through Eq. (13), amounts $x_{j}$ ) of the metal or proton surface complexes or adsorbed anions. Hence, the $2 \mathrm{p} K$ and the $1 \mathrm{p} K$ SCMs appear to be thermodynamically (but not physicochemically) equivalent in the GEM framework (see also [14]).

In view of the above reasoning, the standard-state $G^{\circ}$ and $\log K$ values of $\mathrm{U}(\mathrm{VI})$ surface species on $\mathrm{SiO}_{2}$, am or quartz surfaces (Table 4), backed up by EXAFS studies and in situ TRLIFS observations and obtained in the framework of $2 \mathrm{p} K$ TLM (Table 2), appear to reflect chemical reality and macroscopic data well enough to be considered as the candidates for extension of the "uniform adsorption thermodynamic database". The data appear to be connected with one $\Gamma_{\max }$ parameter $\left(0.14\right.$ to $0.18 \mathrm{~nm}^{-1}$, applicable to both quarts and silica surfaces) that seems to define a surface coverage of mononuclear $\mathrm{U}(\mathrm{VI})$ surface complexes, above Brought to you by | Lib4RI Eawag-Empa Authenticated 
which the formation of polinuclear U(VI) surface species becomes important. This thermodynamic dataset (Tables 2 and 4) is expected to describe adsorption of U(VI) onto quartz-water and silica-water interfaces in presence or absence of $\mathrm{CO}_{2}$ in a wide range of $\mathrm{pH}$, solid/water ratios, total U(VI) concentrations, and ionic strength. As shown in Sections 6 and 7, GEM modelling of titration data for sufficiently well characterised samples $[2,29,34]$ suggests that uncertainty of $\log K$ values is about \pm 0.3 units $\left(1.7 \mathrm{~kJ} \mathrm{~mol}^{-1}\right.$ in $G_{298}^{o}$ values), except the hypothetical ternary $\gg \mathrm{OULCH}^{+4}$ complex, for which at least $1 \log K$ unit uncertainty must be assumed.

The standard molal $G_{298}^{\mathrm{o}}$ values of surface complexes (Table 4) are comparable with $G_{298}^{\mathrm{o}}$ of aqueous species and minerals at the level of elemental chemical potentials (Eq. (30)). Direct comparison of the surface complex stability becomes possible, even between different mineral-water interfaces, only if stoichiometries of surface complexes are the same. In certain cases, $\Delta_{\mathrm{r}} G_{298}^{\mathrm{o}}$ for different stoichiometries can also be compared. For instance, $\log K$ values for the NEM species $>\mathrm{O}_{0.5} \mathrm{UO}_{2} \mathrm{OH}^{\circ}$ (Eqs. $(17,18)$ ) and the TLM species $>\mathrm{OUO}_{2}{ }^{\circ}$ (Eq. (22)) can be compared because they differ in one $>\mathrm{O}_{0.5} \mathrm{H}^{\circ}$ species and one $\mathrm{H}_{2} \mathrm{O}$ ( $\log a=1.744$ and $\log a=0$ at the reference state, respectively). The $\log K$ differences (see Tables 1 and 4, $-6.56-$ $1.744+7.5 \approx-0.80$ and $-5.57-1.744+7.5 \approx+0.19$ ), respectively, point that the NEM $1>\mathrm{O}_{0.5} \mathrm{UO}_{2} \mathrm{OH}^{\circ}$ species is ca. $0.8 \mathrm{pK}$ units weaker and the $2>\mathrm{O}_{0.5} \mathrm{UO}_{2} \mathrm{OH}^{\circ}$ species is $c a$. 0.2 units stronger than the $\mathrm{TLM}>\mathrm{OUO}_{2}{ }^{\circ}$ surface complex. The NEM SCM operates with two neutral uranyl surface complexes of different stability, counterbalanced by the artificial $\Gamma_{\max }$ constraints for two site types that have been introduced to improve the fits at various $\mathrm{U}(\mathrm{VI})$ surface coverages. The TLM formulation (Table 4), instead, distributes adsorbed uranyls on one surface type between four surface complexes of different stoichiometry and charge with one $\Gamma_{\max }$ parameter for mononuclear surface uranyl hydroxocomplexes. Inspection of Figs. 4 to 6 shows why uranyl surface speciation must depend strongly on the total dissolved uranium $\mathrm{U}_{\mathrm{AQ}}, p_{\mathrm{CO}_{2}}$ and $\mathrm{pH}$ parameters: this is merely a consequence of different elemental stoichiometries and formula charges, because chemical potential of the "charge" stoichiometry unit contributes to a species chemical potential in Eq. (30). For instance, stability of the $\gg \mathrm{ULH}^{-2}$ and $\gg \mathrm{ULCH}^{-4}$ species is greatly enhanced at alkaline $\mathrm{pH}$, while their concentrations are counterbalanced by the Coulombic term due to negative surface charge.

The "top-down" modelling exercise (Sect. 6) points out that LMA and GEM SCMs can easily be inter-converted using Eq. (7), at least when monodentate surface species are considered. However, conversion from $K^{\text {int }}$ to $\mathrm{K}$ and then to $G_{298}^{o}$ for bidentate surface complexes is not so straightforward because in the LMA SCMs, bidentate species were treated in the mass balance as consuming either one [31] or two [26] surface sites, while the respective surface complexation reactions were written with one "bidentate" surface $\mathrm{OH}$ group. For that reason, reactions (22) and (27) to (29) are written as consuming two primary $>\mathrm{O}_{0.5} \mathrm{H}^{\circ}$ species, and two sets of converted constants are provided in Table 4 for the possible LMA implementation at site density parameter $\Gamma_{\mathrm{C}}=4.6$ sites $\mathrm{nm}^{-2}$. If "double" hydroxyl sites will be con- sidered as monodentate species in the LMA mass balance, then one conversion using Eq. (7) is sufficient; if two sites per complex are to be consumed in the mass balance, then a second conversion step is necessary. However, in GEM implementation, stoichiometries of surface complexes are taken directly into the elemental mass balance together with that of aqueous species, minerals etc. Hence, in the linear adsorption region (where SAT corrections are not necessary), the "dentateness" of surface complexes plays no role, although it must be important when the SAT corrections are involved (for this reason, we expressed $\Gamma_{\max }$ in "species per unit area" $\mathrm{nm}^{-2}$ units, not in "sites per unit area"). This topic obviously needs to be addressed in detail, especially in the case of competitive SAT (Eq. (11)).

Another important (and intensively debated) issue is how and to what extent the inherent heterogeneity of mineral surfaces must be reflected in the SCMs, and what are activity coefficients of surface-bound species. Even on the phenomenological level, the subject appears to be quite complicated and tightly related to sorption kinetics. According to Barrow et al. [43], reactions between aqueous ions and (soil) mineral surfaces change both the surface charge and the $\mathrm{pH}$ in aqueous phase, and these changes have effects analogous to the lateral interactions which may occur for reactions between uncharged molecules and surfaces. There may also be true heterogeneity: for short-term reaction, e.g. iron oxide surfaces appear to be heterogeneous with respect to reaction with cations but not anions (for cations, possibly caused by $\mathrm{Fe}$ vacancies leading to more negatively charged sites). Long-term reaction also shows evidence of heterogeneity in that both cations and anions may continue to react with iron oxides for a long period of time (this includes intraparticle diffusion of sorbed cations or anions and may be an issue in nuclear waste disposal related studies).

In this context, we believe that further development of the SAT concept may eventually lead to a much better description of the above-mentioned irreversible processes in the time-dependent "process extent" modelling on the basis of the partial equilibrium principle.

Overall, using the GEM approach (for instance, in GEMSelektor implementation), the "sorption continuum" involving radionuclides on mineral-water interfaces can be modelled (similar to solid solution-aqueous solution systems) only in chemical elemental stoichiometry, without additional balance constraints for surface sites. This opens a feasible way towards future development of a "uniform thermodynamic database" for radionuclide sorption in form of a consistent extension of existing thermochemical databases for aqueous species, gases and minerals. Should the GEM SCMs be opposed to the earlier developed and still commonly used LMA SCMs? The message of this article is that the new thermodynamic approach to sorption modelling is useful in both GEM and LMA modelling techniques, which are complementary rather than mutually exclusive.

The proposed standard-state conversions between $K^{\text {int }}$, $K$ and $G^{\circ}$ values of surface complexes and separation of the sample-mineral-surface-specific maximum site density parameters into the SAT corrections are expected to be helpful, regardless of which particular numerical technique (GEM or LMA) is used to model macroscopic titration data. In compilation of the uniform sorption thermodynamic database, 
either the "top-down" approach (conversion of published LMA-fitted $K^{\text {int }}$ into standard $G^{\circ}$ values), or the "bottomup" approach (direct GEM-fitting of $G^{\text {o }}$ values for selected stoichiometries against experimental $K_{\mathrm{d}}$ or adsorbed fraction data, afterwards conversion into $K^{\text {int }}$ for usage in LMA codes) can be applied wherever appropriate. Numerical examples in this contribution just illustrate how the "topdown" and "bottom-up" approaches may work, rather than pretend to discuss all the experimental details, quality of surface spectroscopic data, complex physicochemical phenomena that occur during U(VI) adsorption on silica and quartz surfaces, or to compile a critical review of the vast literature on $\mathrm{U}(\mathrm{VI})$ sorption on oxides and in subsurface.

In future, application of the growing radionuclide adsorption thermodynamic database using SCMs implemented either in GEM or LMA codes would facilitate evaluation of the "smart $K_{\mathrm{d}}$ " ranges relevant in the performance assessment studies, as well as in interpretation of new geochemical or experimental data, correlation and prediction of thermodynamic adsorption constants.

\section{Appendix}

Auxiliary data: standard molal (molar) Gibbs energies used in conversions between $\log K$ and $G_{298}^{\text {o }}$ ([37, 38]; Nagra/PSI database [36], GEM-Selektor version).

\begin{tabular}{llll}
\hline Species & \multicolumn{1}{c}{$\begin{array}{c}G_{298}^{\mathrm{o}} \\
\mathrm{kJ} \mathrm{mol}^{-1}\end{array}$} & Species & $\begin{array}{c}G_{298}^{\mathrm{o}} \\
\mathrm{kJ} \mathrm{mol}^{-1}\end{array}$ \\
\hline $\mathrm{CO}_{2}{ }^{\circ}$ & -386.014 & $\mathrm{Na}^{+}$ & -261.881 \\
$\mathrm{CO}_{3}{ }^{-2}$ & -527.982 & $\mathrm{SiO}_{2}{ }^{\circ}$ & -833.411 \\
$\mathrm{NO}_{3}{ }^{-}$ & -110.905 & $\mathrm{UO}_{2}{ }^{+2}$ & -952.613 \\
$\mathrm{OH}^{-}$ & -157.270 & $\mathrm{H}_{2} \mathrm{O}$ (water) & -237.183 \\
\hline
\end{tabular}

Acknowledgment. This text has been improved thanks to substantial and constructive comments and suggestions of two anonymous reviewers, as well as to stimulating discussions with Bart Baeyens, Urs Berner, Mike Bradbury, Laurent Charlet, Wolfgang Hummel, Tres Thoenen, Erich Wieland and other colleagues. Partial financial support from NAGRA (Swiss National Cooperative for the Disposal of Radioactive Waste) is gratefully appreciated.

\section{References}

1. Banwart, S. A.: Aqueous speciation at the interface between geological solids and groundwater. In: Modelling in aquatic chemistry. (Grenthe, I., Puigdomenech, I., eds.) NEA OECD, Paris (1997) p. 245.

2. Davis, J. A. (ed.): Surface complexation modeling of uranium (VI) adsorption on natural mineral assemblages, Report NUREG/ CR-6708, U.S.Nuclear Regulatory Commission, Washington, D.C. (2001) p. 214.

3. Parkhurst, D. L., Appelo, C. A. J.: User's guide to PHREEQC (version 2) - A computer program for speciation, batch-reaction, one-dimensional transport, and inverse geochemical calculations. U.S.G.S. Water-Resources Investigations Report 99-4259, Denver, Colorado (1999) p. 312.

4. Herbelin, A. L., Westall, J. C.: FITEQL: A computer program for determination of chemical equilibrium constants from experimental data. Department of Chemistry, Oregon State University, Corvallis, Oregon (1996).

5. Goldberg, S.: Sensitivity of surface complexation modeling to the surface site density parameter. J. Colloid Interf. Sci. 145, 1 (1991).
6. Christl, I., Kretzschmar, R.: Competitive sorption of copper and lead at the oxide-water interface: Implications for surface site density. Geochim. Cosmochim. Acta 63, 2929 (1999).

7. Davis, J. A., Kent, D. B.: Surface complexation modeling in aqueous geochemistry. In: Mineral-water interface chemistry. (Hochella, M. F., White, A. F., eds.) Vol. 23, Rev. Mineral, Washington, D.C. (1990) p. 177.

8. Zachara, J. M., Westall, J. C.: Chemical modeling of ion adsorption in soils. In: Soil Physical Chemistry. 2nd edn. (Sparks, D. L., ed.) CRC Press, Boca Raton, FL (1999).

9. Dzombak, D. A., Morel, F. M. M.: Surface complexation modeling. Hydrous ferric oxide. Wiley Interscience, New York (1990).

10. Sahai, N., Sverjensky, D. A.: Evaluation of internally consistent parameters for the triple-layer model by the systematic analysis of oxide surface titration data. Geochim. Cosmochim. Acta 61, 2801 (1997).

11. Karpov, I. K., Chudnenko, K. V., Kulik, D. A.: Modeling chemical mass-transfer in geochemical processes: Thermodynamic relations, conditions of equilibria and numerical algorithms. Am. J. Sci. 297, 767 (1997).

12. Kulik, D. A., Kersten, M., Heiser, U., Neumann, T.: Application of Gibbs energy minimization to model early-diagenetic solid-solution aqueous-solution equilibria involving authigenic rhodochrosites in anoxic Baltic Sea sediments. Aquat. Geochem. 6, 147 (2000).

13. Kulik, D. A., Kersten, M.: Aqueous solubility diagrams for cementitious waste stabilization systems: II. End-member stoichiometries of ideal calcium silicate hydrate solid solutions. J. Am. Ceram. Soc. 84, 3017 (2001).

14. Kulik, D. A.: Thermodynamic properties of surface species at the mineral-water interface under hydrothermal conditions: A Gibbs energy minimization triple layer model of rutile in $\mathrm{NaCl}$ electrolyte to $250^{\circ} \mathrm{C}$. Geochim. Cosmochim. Acta 64, 3161 (2000). Errata: 65, 2027 (2001).

15. Kulik, D. A.: A Gibbs energy minimization approach to modelling sorption equilibria at the mineral-water interface: Thermodynamic relations for multi-site-surface complexation. Amer. J. Sci. 302, 227 (2002)

16. Anderson, G. M., Crerar, D. A.: Thermodynamics in geochemistry: The equilibrium model. Oxford Univ. Press, New York (1993).

17. Kulik, D. A.: New aspects of thermodynamic sorption modelling introduced by Gibbs energy minimisation. Miner. Mag. 62A, 822 (1998).

18. Tamura, H., Mita, K., Tanaka, A., Makoto, I.: Mechanism of hydroxylation of metal oxide surfaces. J. Colloid Interf. Sci. 243, 202 (2001).

19. Sahai, N., Sverjensky, D. A.: Solvation and electrostatic model for specific electrolyte adsorption. Geochim. Cosmochim. Acta 61, 2827 (1997)

20. Stumm, W.: Chemistry of the solid-water interface, WileyInterscience, New York (1992) p. 428.

21. Adamson, A. W.: Physical Chemistry of Surfaces. $5^{\text {th }}$ ed., John Wiley and Sons, New York (1990) p. 664.

22. Kulik, D. A., Aja, S. U., Sinitsyn, V. A., Wood, S. A.: Acid-base surface chemistry and sorption of some lanthanides on $\mathrm{K}^{+}$saturated Marblehead illite: II. A multisite-surface complexation modeling. Geochim. Cosmochim. Acta 64, 195 (2000).

23. Benjamin, M. M., Leckie, J. O.: Multiple-site adsorption of $\mathrm{Cd}$, $\mathrm{Cu}, \mathrm{Zn}$, and $\mathrm{Pb}$ on amorphous iron oxyhydroxide. J. Colloid Interf. Sci. 79, 209 (1981).

24. Kosmulski, M.: Chemical properties of material surfaces. Marcel Dekker, New York (2001) p. 753.

25. Parks, G. A.: Surface energy and adsorption at mineral/water interfaces: An introduction. In: Mineral-water interface geochemistry. (Hochella, M. F., White, A. F., eds.) Rev. Miner. 23, Miner. Soc. America, Washington, D.C. (1990) p. 133.

26. Waite, T. D., Davis, J. A., Payne, T. E., Waychunas, G. A., Xu, N.: Uranium(VI) adsorption to ferrihydrite: Application of a surface complexation model. Geochim. Cosmochim. Acta 58, 5465 (1994).

27. Payne, T. E., Lumpkin, G. R., Waite, T. D.: Uranium VI adsorption on model minerals: Controlling factors and surface complexation modeling. In: Adsorption of metals by geomedia. (Jenne, E. A., ed.) Academic Press, San Diego (1998) p. 75. 
28. Michard, P., Guibal, E., Vincent, T., Le Cloirec, P.: Sorption and desorption of uranyl ions by silica gel: $\mathrm{pH}$, particle size, and porosity effects. Microp. Mater. 5, 309 (1996).

29. Gabriel, U., Charlet, L., Schlaepfer, C. W.: In situ speciation of uranium (VI) at the silica-water interface: A combined TRLIFS and surface complexation study. In: Water-rock interactions, ore deposits, and environmental geochemistry: A tribute to David A. Crerar. (Hellmann, R., Wood, S. A., eds.) Geochemical Society, St. Louis (2001) Spec. Publ. No. 7, p. 423

30. Pabalan, R. T., Turner, D. R., Bertetti, F. P., Prikryl, G. D.: Uranium VI sorption onto selected mineral surfaces: Key geochemical parameters. In: Adsorption of metals by geomedia. (Jenne, E. A., ed.) Academic Press, San Diego (1998) p. 99.

31. Gabriel, U., Charlet, L., Schlaepfer, C. W., Vial, J. C., Brachmann, A., Geipel, C.: Uranyl surface speciation on silica particles studied by time-resolved laser-induced fluorescence spectroscopy. J. Colloid Interf. Sci. 239, 358 (2001).

32. Sylwester, E. R., Hudson, E. A., Allen, P. G.: The structure of uranium(VI) sorption complexes on silica, alumina and motmorillonite. Geochim. Cosmochim. Acta 64, 2431 (2000).

33. Reich, T., Moll, H., Arnold, T., Denecke, M. A., Henning, C., Geipel, G., Bernhard, G., Nitsche, H., Allen, P. G., Bucher, J. J., Edelstein, N. M., Shuh, K.: An EXAFS study of uranium(VI) sorption onto silica gel and ferrihydrite. J. Spectrosc. Rel. Phenom. 96, 237 (1998).

34. Turner, G. D., Zachara, J. M., McKinley, J. P., Smith, S. C.: Surfacecharge properties and $\mathrm{UO}_{2}{ }^{2+}$ adsorption on a subsurface smectite. Geochim. Cosmochim. Acta 60, 3399 (1996).
35. Lieser, K. H., Quandt-Klenk, S., Thybusch, B.: Sorption of uranyl ions on hydrous silicon dioxide. Radiochim. Acta 57, 45 (1992).

36. Hummel, W., Berner, U. R., Curti, E., Pearson, F. J., Thoenen, T.: Nagra/PSI chemical thermodynamic data base 01/01. Universal Publishers/ uPUBLISH.com, USA (2002) p. 589.

37. Shock, E. L., Sassani, D. C., Willis, M., Sverjensky, D. A.: Inorganic species in geologic fluids: Correlations among standard molal thermodynamic properties of aqueous ions and hydroxide complexes. Geochim. Cosmochim. Acta 61, 907 (1997).

38. Shock, E. L., Sassani, D. C., Betz, H.: Uranium in geologic fluids: Estimates of standard partial molal properties, oxidation potentials, and hydrolysis constants at high temperatures and pressures. Geochim. Cosmochim. Acta 61, 4245 (1997).

39. Langmuir, D.: Aqueous environmental geochemistry. Prentice Hall, NJ (1997) p. 600.

40. Lutzenkirchen, J.: Surface complexation models of adsorption. In: Encyclopedia of surface and colloid science. Marcel Dekker, New York (2002) p. 5028 (www.decker.com).

41. Hayes, K. F., Redden, G., Ela, W., Leckie, J. O.: Surface complexation models: An evaluation of model parameter estimation using FITEQL and oxide mineral titration data. J. Colloid Interf. Sci. 142, 448 (1991).

42. Katz, L. E., Hayes, K. F.: Surface complexation modeling. I. Strategy for modeling monomer complex formation at moderate surface coverage. J. Colloid Interf. Sci. 170, 477 (1995).

43. Barrow, N. J., Bruemmer, G. W., Strauss, R.: Effects of surface heterogeneity on ion adsorption by metal oxides and by soils. Langmuir 9, 2606 (1993). 